Supporting Information for:

\title{
Polyphosphonate-based Macromolecular RAFT-CTA enables the synthesis of well-defined block copolymers using vinyl monomers
}

\author{
Diego A. Resendiz-Lara, ${ }^{\dagger}$ and Frederik R. Wurm*, ${ }^{\dagger}$ \\ $\dagger$ Sustainable Polymer Chemistry, Department of Molecules and Materials, MESA+ Institute for \\ Nanotechnology, Faculty of Science and Technology, Universiteit Twente, PO Box 217, 7500 AE \\ Enschede, The Netherlands. \\ E-mail: frederik.wurm@utwente.nl
}




\section{Contents}

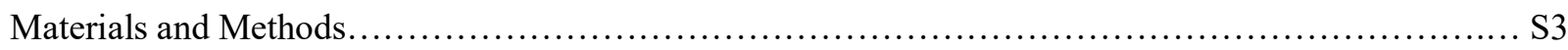

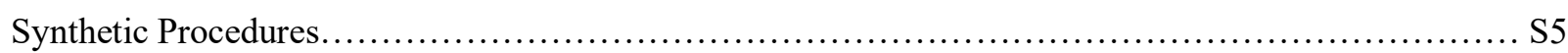

Kinetics of the polymerization of ethyl phosphonate to the PEtPn macro-CTA agent. ................S5

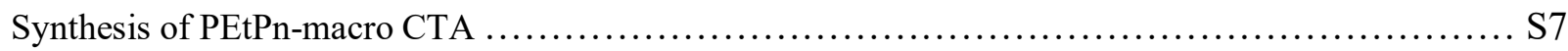

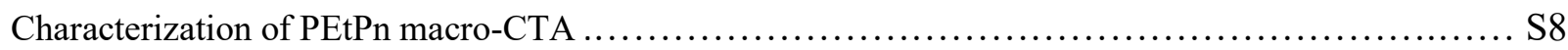

Calculation of the hydrophilic-lipophilic balance (HLB) according to the Method of Griffin...............S10

Kinetics of RAFT polymerization of DMA and PEtPn macro-CTA........................... S11

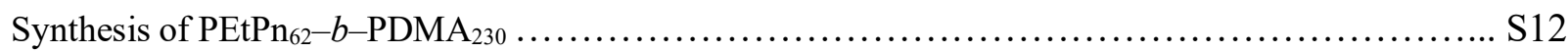

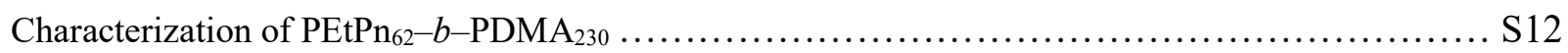

Kinetics of RAFT polymerization of ethyl methacrylate and PEtPn macro-CTA................. S16

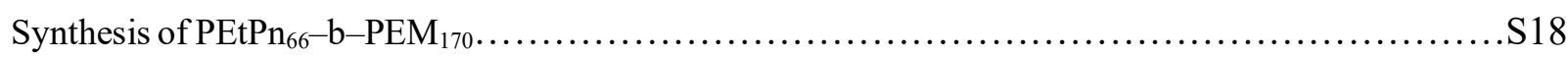

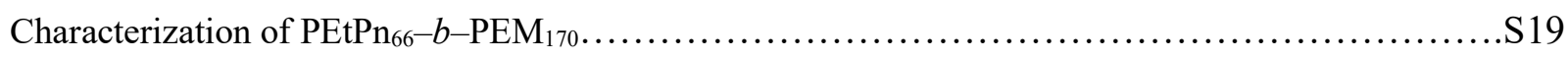

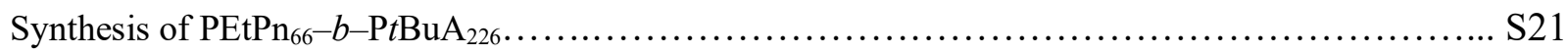

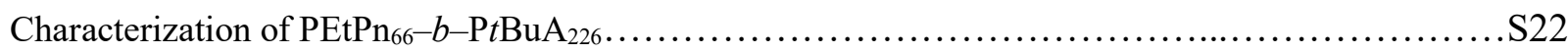

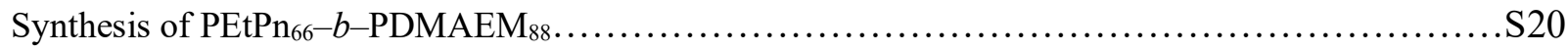

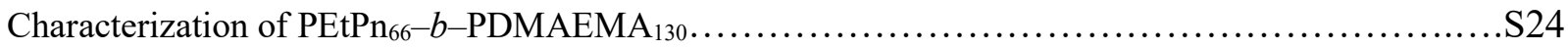

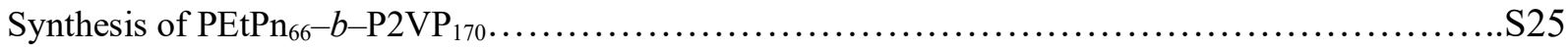

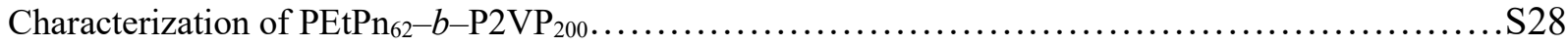

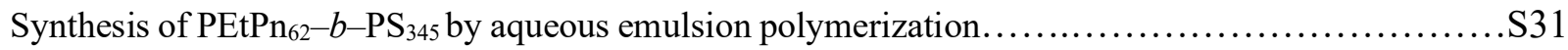

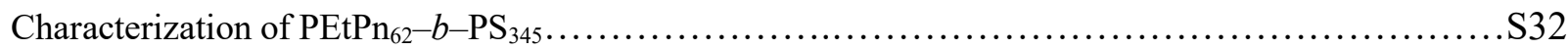

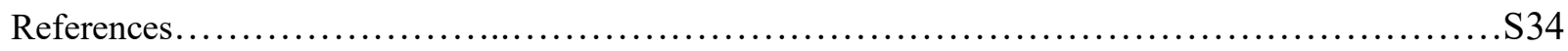




\section{Materials and Methods}

All manipulations involving air- and moisture-sensitive reagents were carried out either under an atmosphere of nitrogen gas using standard vacuum line and Schlenk techniques or under an atmosphere of nitrogen within an M. Braun glovebox MB-BL-01 maintained at $<0.1 \mathrm{ppm}$ of $\mathrm{H}_{2} \mathrm{O}$ and $<0.1 \mathrm{ppm}$ of $\mathrm{O}_{2}$. All solvents and chemicals were purchased from Sigma Aldrich, Acros Organics, Fluka or Fisher Scientific and used as received unless otherwise stated. Anhydrous deuterated chloroform ( $\geq 99.8$ atom \% D) and dichloromethane ( $\geq 99.8 \%$ ) were purchased from Sigma Aldrich and stored over activated molecular sieves (4 A). Workup of polymeric materials was performed in air using lab-grade solvents. MilliQ water was purified from a MilliQ Advange A10 purification system (Millipore, Billerica, Ma, USA).

1,8-diazabycyclo[5.4.0]undec-7-ene (DBU, Sigma Aldrich, 98\%) was distilled from $\mathrm{CaH}_{2}$ and stored over molecular sieves ( 3 and $4 \AA$ ) under nitrogen at $-40^{\circ} \mathrm{C}$.

4-Cyano-4-[[(dodecylthio)carbonothioyl]thio]pentanoic acid (TCI, $>97.0 \%$ (HPLC)) was reduced to 2cyano-5-hydroxypentan-2-yl dodecyl trithiocarbonate via a literature method ${ }^{\mathrm{S} 1}$ and was dried over $\mathrm{P}_{2} \mathrm{O}_{5}$ (Sigma Aldrich, 99.0\%) for 6 days.

2-ethyl-2-oxo-1,3,2-dioxaphospholane (ethyl ethylene phosphonate, EtPn) ( $\geq 99.0 \%$ determined by ${ }^{31} \mathrm{P}$ NMR spectroscopy analysis) was synthesized via a literature method ${ }^{\mathrm{S} 2}$ and stored under nitrogen at $-40{ }^{\circ} \mathrm{C}$. To remove the stabilizers from dioxane (Sigma Aldrich, $\geq 99.0 \%$ ), $N, N$-dimethylacrylamide (DMA, Sigma Aldrich, 99.0\%), ethyl methacrylate (DMA, Sigma Aldrich, 99.0\%), 2-(dimethylamino)ethyl acrylate (DMAEMA, Sigma Aldrich, 98.0\%) and tert-butyl acrylate ( $t \mathrm{BuA}$, Sigma Aldrich, 98.0\%), these were passed through basic alumina plugs in Pasteur pipettes before use. Styrene (S, Sigma Aldrich, $\geq 99.0 \%$ ) and 2-vinyl pyridine (2VP, Sigma Aldrich, 97.0\%) were dried over $\mathrm{CaH}_{2}$ (Sigma Aldrich, 95.0\%), and distilled under reduced pressure, and stored at $-40{ }^{\circ} \mathrm{C}$.

Azobisisobutyronitrile (AIBN, Sigma Aldrich, 98.0\%) was recrystallized from methanol (three times), dried at reduced pressure, and stored at $5^{\circ} \mathrm{C}$. 


\section{Nuclear Magnetic Resonance (NMR) Spectroscopy}

${ }^{1} \mathrm{H}-,{ }^{31} \mathrm{P}-$, and DOSY NMR spectra were measured on a $400 \mathrm{MHz}$ Bruker AVANCE III Nanobay with a BBFO probe or a $600 \mathrm{MHz}$ Bruker AVANCE III system with a BBO probe. The temperature was kept at $298 \mathrm{~K}$ during the measurements. As deuterated solvent $\mathrm{CDCl}_{3}$ was used. MestReNova 10.0.2 from Mestrelab Research S.L. was used for the analysis of all measured spectra. The spectra were calibrated against the solvent signal $\left(\mathrm{CDCl}_{3}: \delta \mathrm{H}=7.26 \mathrm{ppm}\right)$

\section{Size Exclusion Chromatography (SEC)}

GPC measurements were performed in $\operatorname{DMF}(0.1 \mathrm{M} \mathrm{LiCl})$ at $60^{\circ} \mathrm{C}$ with an Agilent Technologies 1260 Infinity II, PSS SECcurity system at a flow rate of $1 \mathrm{~mL} \mathrm{~min}{ }^{-1}$. Each sample injection volume was $50 \mu \mathrm{L}$, performed by Agilent 1260-ALS autosampler. 2 GRAM columns (PSS) in series with dimensions of $8 \times$ $300 \mathrm{~mm}^{2}, 10 \mu \mathrm{m}$ particle size, and pore sizes of resp. 1000 and $30 \AA$, including a $10 \mu \mathrm{m}$ GRAM guard column were employed. Calibration was carried out using polystyrene standards supplied by Polymer Standards Service. The GPC data were plotted using the software OriginPro $8 G$ from OriginLab Corporation.

\section{Dynamic Light Scattering (DLS)}

Dynamic light scattering (DLS) was performed on a Zetasizer Nano S90 submicron particle sizer (Malvern Panalytical, UK) at a fixed angle of $90^{\circ}$ and a laser diode running at $633 \mathrm{~nm}$.

\section{Scanning Electron Microscopy (SEM)}

Samples for SEM was prepared by drop-casting the sample solution onto a graphite SEM sample stub. Imaging was performed using a JEOL JSM-7610F plus ultra-high resolution SEM microscope operated at $1.5 \mathrm{kV}$ accelerating voltage to obtain the different structures/images. 


\section{Synthetic Procedures}

Kinetics of the polymerization of ethyl phosphonate to the PEtPn macro-CTA agent.<smiles>CCP1(=O)OCCO1</smiles>

Scheme S1. Synthesis of PEtPn macro-CTA by ring-opening polymerization of ethyl phosphonate by 2cyano-5-hydroxypentan-2-yl dodecyl trithiocarbonate as the initiator.

Ethyl ethylene phosphonate (400 mg, $2.94 \mathrm{mmol}, 60 \mathrm{eq}$ ) and 2-cyano-5-hydroxypental-2-yl dodecyl carbonotrithioate (19 mg, $0.049 \mathrm{mmol}, 1 \mathrm{eq})$ were dissolved in anhydrous $\mathrm{CH}_{2} \mathrm{Cl}_{2}(0.74 \mathrm{~mL})$ in an ovendried $4 \mathrm{~mL}$ vial equipped with a magnetic stirring bar. The reaction mixture was homogenized by stirring at $20{ }^{\circ} \mathrm{C}$ followed by the addition of DBU $(22 \mu \mathrm{L}, 55.9 \mathrm{mg}, 0.37 \mathrm{mmol}, 3 \mathrm{eq})$, and the solution was stirred at room temperature. The sampling involved periodic extraction of aliquots from the reaction mixture, followed by dissolution in $\mathrm{CDCl}_{3}$, which is a good solvent for both ethyl ethylene phosphonate and the corresponding polymer. Each sample was analyzed by ${ }^{1} \mathrm{H}$ and ${ }^{31} \mathrm{P}$ NMR spectroscopy (the chemical shift of the cyclic monomer (52.5 ppm) to the corresponding linear phosphonic acid ester (35.2 ppm) was observed as previously reported ${ }^{\mathrm{S} 2}$ and $\operatorname{SEC}$ in $\operatorname{DMF}(0.1 \mathrm{M} \mathrm{LiCl})$ was conducted at $60^{\circ} \mathrm{C}$. 
Table S1. Kinetics of the polymerization of ethyl ethylene phosphonate by 2-cyano-5-hydroxypentan-2-yl dodecyl trithiocarbonate as the initiator to the PEtPn macro-CTA agent.

\begin{tabular}{|c|c|c|c|c|c|c|}
\hline Entry & $\begin{array}{c}{[\mathrm{M}]_{\text {monomer: }}} \\
{[\mathrm{M}]_{\text {initator }}}\end{array}$ & $\begin{array}{c}\text { Time } \\
(\mathrm{min})\end{array}$ & $\begin{array}{c}\text { Conv. } \\
(\%)^{a}\end{array}$ & $M_{\mathrm{n} \text { theo }^{b}}$ & $M_{\mathrm{n} \mathrm{SEC}}{ }^{c}$ & $\Xi^{c}$ \\
\hline 1 & $60: 1$ & 5 & 19 & 1,850 & 1,450 & 1.09 \\
\hline 2 & $60: 1$ & 10 & 30 & 2,700 & 2,000 & 1.08 \\
\hline 3 & $60: 1$ & 15 & 41 & 3,400 & 2,500 & 1.09 \\
\hline 4 & $60: 1$ & 30 & 62 & 4,900 & 3,500 & 1.07 \\
\hline 5 & $60: 1$ & 45 & 75 & 6,000 & 4,300 & 1.06 \\
\hline 6 & $60: 1$ & 60 & 83 & 6,700 & 4,800 & 1.05 \\
\hline 7 & $60: 1$ & 75 & 87 & 7,200 & 5,000 & 1.05 \\
\hline 8 & $60: 1$ & 90 & 90 & 7,400 & 5,300 & 1.05 \\
\hline 9 & $60: 1$ & 120 & 93 & 7,700 & 5,400 & 1.05 \\
\hline 10 & $60: 1$ & 180 & 95 & 7,900 & 5,700 & 1.06 \\
\hline
\end{tabular}

${ }^{a}$ Calculated by ${ }^{31} \mathrm{P}$ NMR spectroscopy analysis.

${ }^{b}\left[\left(\left(\right.\right.\right.$ conversion $\left.\left.\left.[\mathrm{M}]_{\mathrm{EtP}} / 100 *[\mathrm{M}]_{\text {monomer: }}[\mathrm{M}]_{\text {initiator }}\right) * 136\right)+389\right]$.

${ }^{c}$ Determined by SEC in DMF $(0.1 \mathrm{M} \mathrm{LiCl})$ at $60{ }^{\circ} \mathrm{C}$.

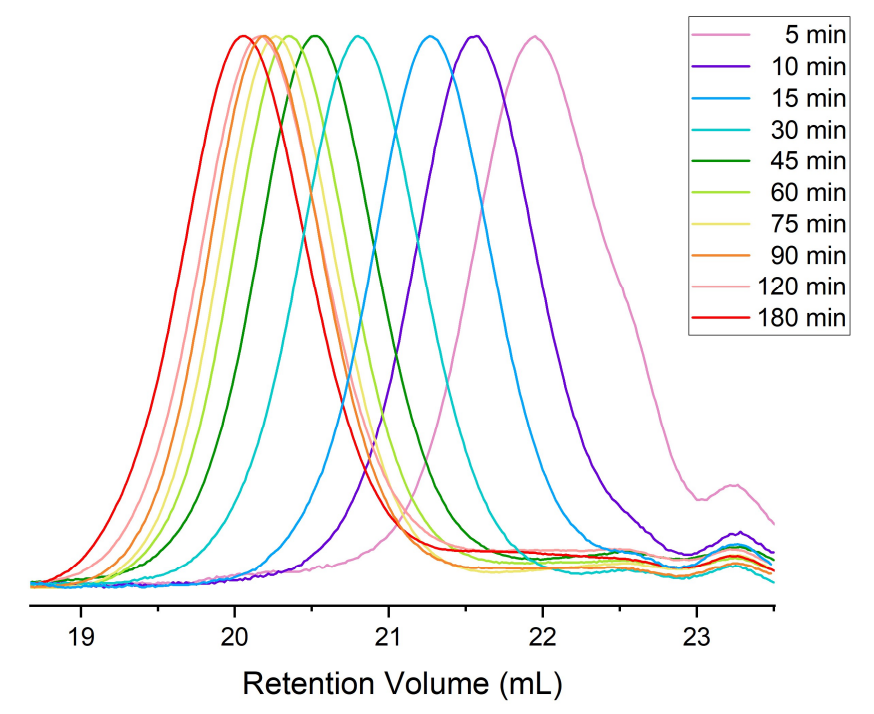

Fig S1. SEC elugrams ( $2 \mathrm{mg} \mathrm{mL}^{-1}$ ) (normalized RI) at different reaction times from the polymerization of ethyl ethylene phosphonate by 2-cyano-5-hydroxypentan-2-yl dodecyl trithiocarbonate as the initiator to the PEtPn macro-CTA agent (measured in DMF $(0.1 \mathrm{M} \mathrm{LiCl})$ at $\left.60{ }^{\circ} \mathrm{C}\right)$. 


\section{Synthesis of PEtPn-macro CTA}

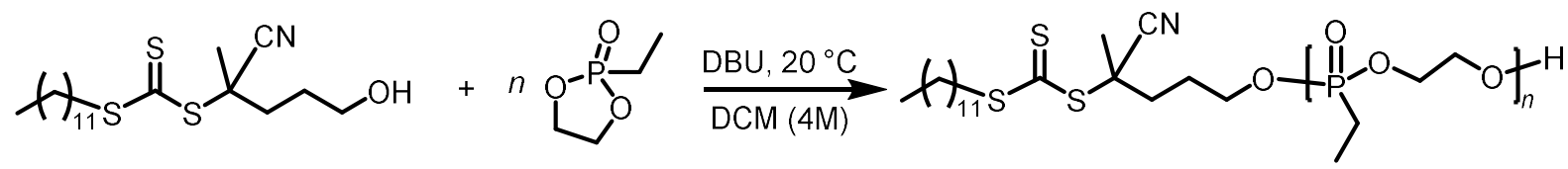

Scheme S2. Synthesis of $\mathrm{PEtPn}_{47}$-CTA by ring-opening polymerization of ethyl ethylene phosphonate by 2-cyano-5-hydroxypentan-2-yl dodecyl trithiocarbonate as the initiator.

NOTE: During the course of this work different samples of PEtPn macro-CTA macromonomer were prepared and variations in the $D P_{n}$ value were determined by end-group analysis by ${ }^{1} \mathrm{H}$ NMR spectroscopy. A representative procedure for the synthesis of a PEtPn macro-CTA is described.

Ethyl ethylene phosphonate (1g, $7.35 \mathrm{mmol}, 60 \mathrm{eq})$ and 2-cyano-5-hydroxypental-2-yl dodecyl carbonotrithioate (48 mg, $0.123 \mathrm{mmol}, 1 \mathrm{eq})$ were dissolved in anhydrous $\mathrm{CH}_{2} \mathrm{Cl}_{2}(1.83 \mathrm{~mL})$ in an ovendried $4 \mathrm{~mL}$ vial equipped with a magnetic stirring bar. The reaction mixture was homogenized by stirring at $20^{\circ} \mathrm{C}$ followed by the addition of DBU $(55 \mu \mathrm{L}, 55.9 \mathrm{mg}, 0.37 \mathrm{mmol}, 3 \mathrm{eq})$ and the solution was stirred at room temperature for $1.5 \mathrm{~h}$ before the reaction mixture was quenched by the rapid addition of an excess of formic acid solution in $\mathrm{CH}_{2} \mathrm{Cl}_{2}\left(20 \mathrm{mg} \mathrm{mL}^{-1}\right)$. The crude product was purified by precipitation into cold diethyl ether $\left(-28^{\circ} \mathrm{C}\right)$ three times, and drying in vacuo to yield $\mathrm{PEtPn}_{66}$ macro-CTA as a yellow viscous liquid (0.95 g, $91 \%)$. The molar mass was determined by end-group analysis ${ }^{1} \mathrm{H}$ NMR spectroscopy by comparing the integral of the $-\mathrm{CH}_{2}$ signal of the CTA agent $(3.33 \mathrm{ppm})$ with the backbone signal (4.25 $\mathrm{ppm})$, similar to as a previous report. ${ }^{\mathrm{S} 3}$ 


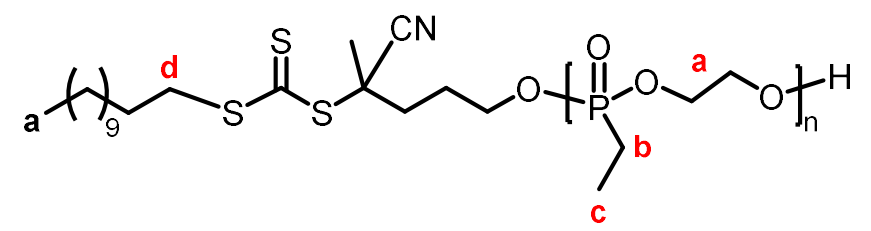

${ }^{1} \mathrm{H}$ NMR $\left(\mathrm{CDCl}_{3}\right): \delta(\mathrm{ppm}) 4.31-4.18(\mathrm{~m}, \mathrm{Ha}) ; 3.34(\mathrm{t}, J=7.4 \mathrm{~Hz}, \mathrm{Hd}, 2 \mathrm{H}), 1.88-1.78(\mathrm{~m}, \mathrm{Hb}), 1.24-1.15$ (m, Hc). End-group ${ }^{1} \mathrm{H}$ NMR spectroscopy analysis showed $D P_{n}=66$ based on 'd' $\left(-\mathrm{CH}_{2}-\mathrm{S}\right)$. (Fig. S3) ${ }^{31} \mathrm{P} \mathrm{NMR}\left(\mathrm{CDCl}_{3}\right): \delta(\mathrm{ppm}) 35.2$ (Fig. S4)

GPC: $M_{\mathrm{n}}=5,400 \mathrm{~g} / \mathrm{mol}, \nexists=1.07$ (Fig. S5)
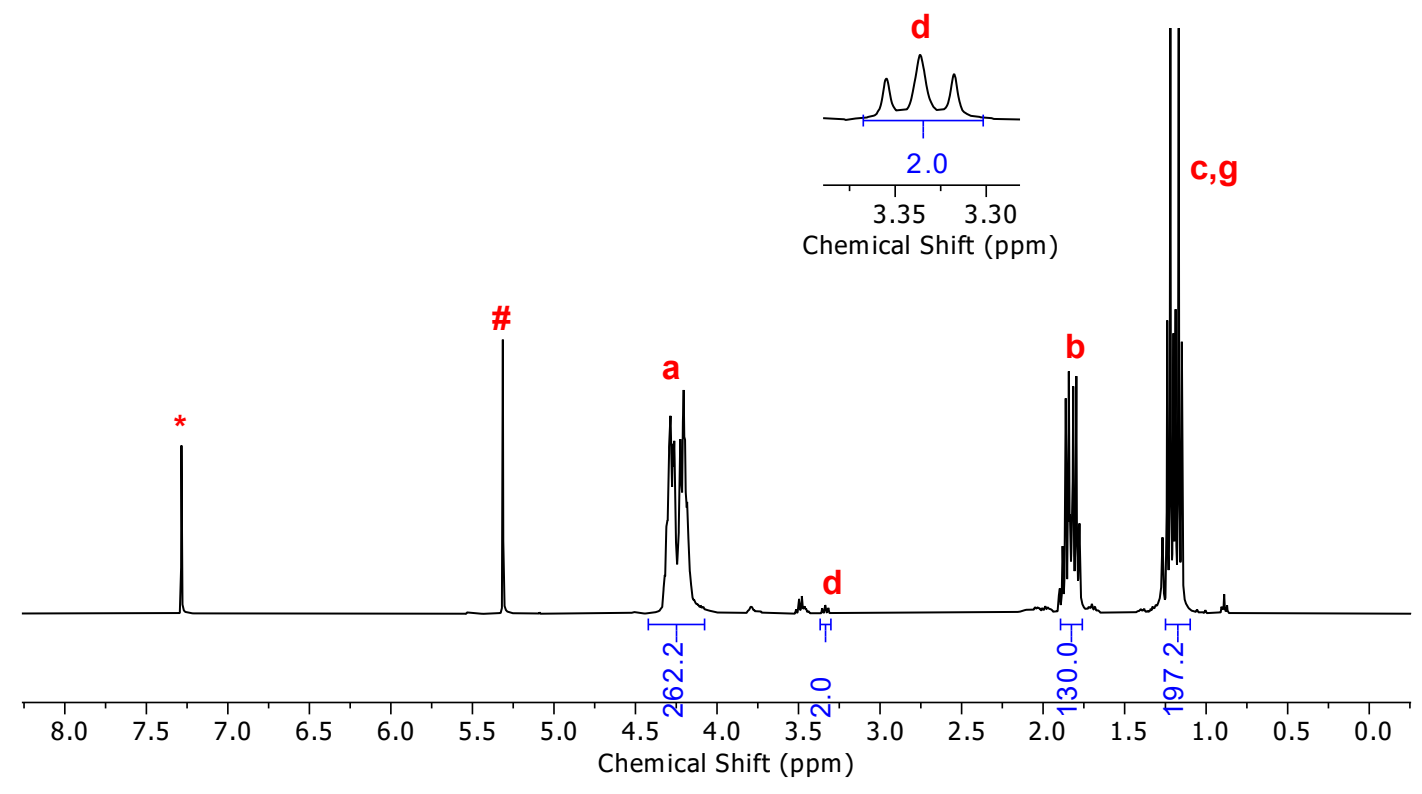

Figure S3. ${ }^{1} \mathrm{H}$ NMR $\left(400 \mathrm{MHz}, \mathrm{CDCl}_{3}\right.$ ) spectrum of $\mathrm{PEtPn}_{66}$ macro-CTA. Deuterated solvent residual signal denote by * and residual $\mathrm{CH}_{2} \mathrm{Cl}_{2}$ by $\#$. 


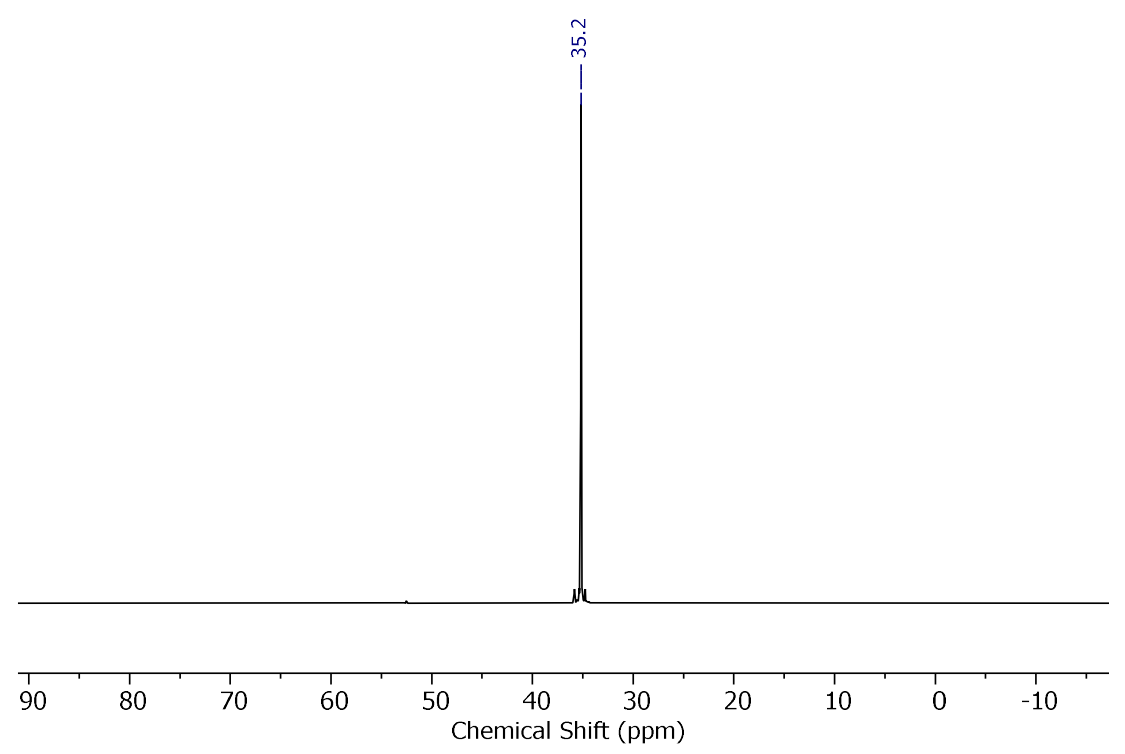

Figure S4. ${ }^{31} \mathrm{P}$ NMR $\left(162 \mathrm{MHz}, \mathrm{CDCl}_{3}\right)$ spectrum of $\mathrm{PEtPn}_{66}$ macro-CTA.

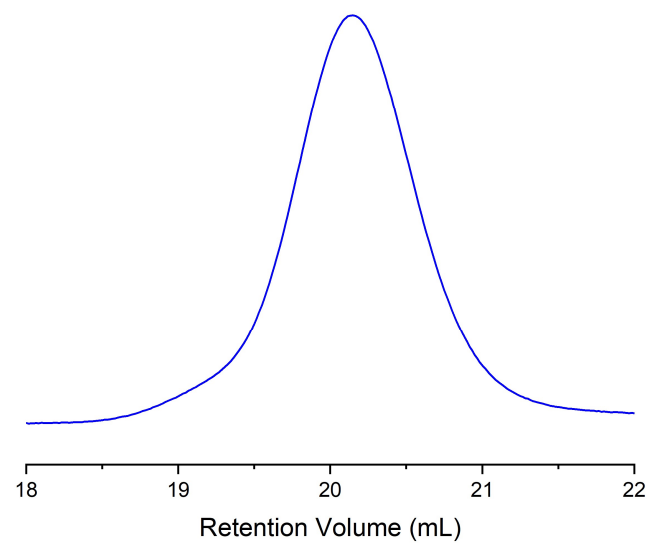

Figure S5. SEC elugram $\left(2 \mathrm{mg} \mathrm{mL}^{-1}\right)$ (normalized RI) of isolated PEtPn 66 macro-CTA (blue, $D=1.04$ ) (measured in $\mathrm{DMF}(0.1 \mathrm{M} \mathrm{LiCl})$ at $\left.60^{\circ} \mathrm{C}\right)$.

Table S2. Synthesis of PEtPn macro-CTAs with different degrees of polymerization.

\begin{tabular}{|c|c|c|c|c|c|c|}
\hline Entry & {$[\mathrm{M}]_{\text {monomer: }}[\mathrm{M}]_{\text {initiator }}$} & $\begin{array}{c}\text { Yield } \\
(\%)\end{array}$ & $M_{\mathrm{n} \text { theo }}{ }^{a}$ & $M_{\mathrm{n} \mathrm{SEC}}{ }^{c}$ & $D P_{n}{ }^{b}$ & $\Xi^{c}$ \\
\hline 1 & $25: 1$ & 92 & 5,000 & 3,300 & 34 & 1.10 \\
\hline 2 & $60: 1$ & 83 & 8,800 & 6,300 & 62 & 1.04 \\
\hline 3 & $55: 1$ & 92 & 9,370 & 6,300 & 66 & 1.04 \\
\hline 4 & $60: 1$ & 93 & 9,900 & 5,900 & 70 & 1.07 \\
\hline
\end{tabular}

${ }^{a}\left[\left(D P_{n} * 136.09\right)+389\right]$.

${ }^{b}$ Calculated by ${ }^{1} \mathrm{H}$ NMR spectroscopy.

${ }^{c}$ Determined by SEC in DMF $(0.1 \mathrm{M} \mathrm{LiCl})$ at $60{ }^{\circ} \mathrm{C}$. 


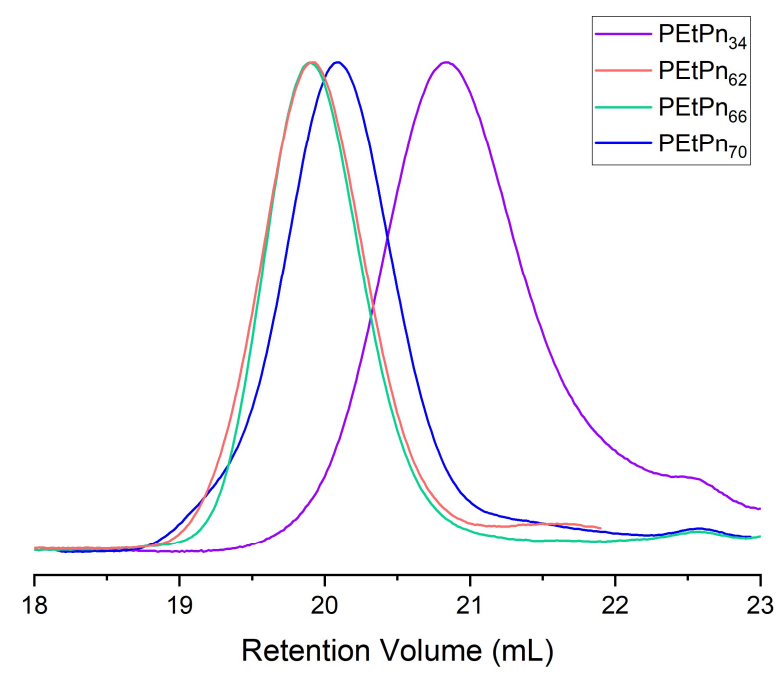

Figure S6. SEC elugrams $\left(2 \mathrm{mg} \mathrm{mL} \mathrm{m}^{-1}\right)$ (normalized RI) of isolated PEtPn macro-CTAs with different degrees of polymerization $D P_{n}=34$ (purple, $D=1.10$ ), $D P_{n}=62$ (orange, $Ð=1.04$ ), $D P_{n}=66$ (green, $Ð=$ 1.04) and $D P_{n}=70$ (blue, $Ð=1.07$ ) (measured in DMF $(0.1 \mathrm{M} \mathrm{LiCl})$ at $60^{\circ} \mathrm{C}$ ).

Calculation of the hydrophilic-lipophilic balance (HLB) according to the Method of Griffin ${ }^{\mathrm{S}-4,5}$

The HLB value of the nonionic surfactant PEtPn macro-RAFT agent was calculated according to the following equation:

$$
H L B=20\left(1-\frac{389}{M_{n \text { PEtPn }}}\right)
$$

With HLB = hydrophilic-lipophilic balance, 389 for the molar mass of 2-cyano-5-hydroxypentan-2-yl dodecyl trithiocarbonate, $M_{n \text { PEtPn }}=$ molar mass of the hydrophilic PEtPn-block calculated by ${ }^{1} \mathrm{H}$ NMR spectroscopy. 


\section{Kinetics of RAFT polymerization of DMA and PEtPn macro-CTA}

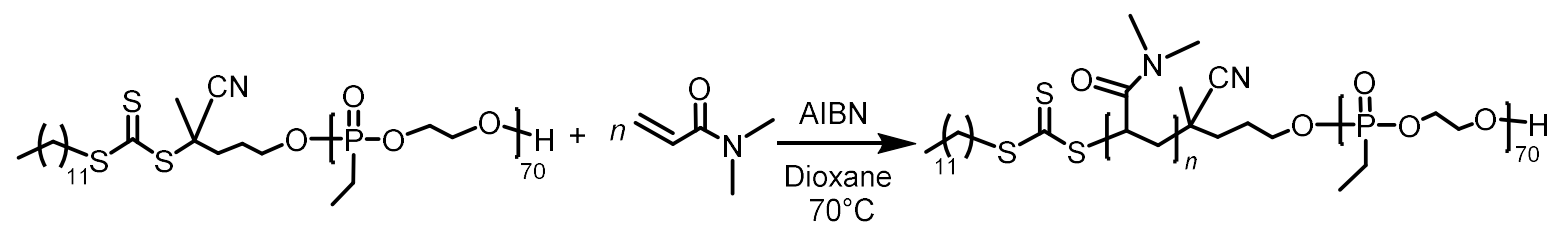

Scheme S3. Synthesis of PEtPn- $b$-PDMA by RAFT polymerization.

$\operatorname{PEtPn}_{70}$ macro-CTA (133 mg, $0.01 \mathrm{mmol}, 1 \mathrm{eq}$ ), N,N-dimethylacrylamide (DMA) (265 mg, 2.68 mmol, 213 eq) were dissolved in dioxane $(0.6 \mathrm{~mL})$ in a Schlenk flask. A stock solution of AIBN $\left(10 \mathrm{mg} \mathrm{mL}^{-1}\right)$ was prepared and AIBN $(0.22 \mathrm{mg}, 0.001 \mathrm{mmol}, 0.1 \mathrm{eq})$ was added. The reaction mixture was stirred at room temperature followed by three freeze-pump-thaw cycles. The Schlenk flask was placed in a preheated oil bath at $70^{\circ} \mathrm{C}$. The sampling involved periodic extraction of aliquots from the reaction mixture, followed by dissolution in $\mathrm{CDCl}_{3}$, which is a good solvent for both the PEtPn macro-CTA and PDMA blocks. Each sample was analyzed by ${ }^{1} \mathrm{H}$ NMR spectroscopy and SEC in DMF $(0.1 \mathrm{M} \mathrm{LiCl})$ at $60{ }^{\circ} \mathrm{C}$.

Table S3. Kinetics of the synthesis of PEtPn- $b$-PDMA block copolymers prepared via RAFT polymerization.

\begin{tabular}{|c|c|c|c|c|c|c|}
\hline Entry & $\begin{array}{c}{[\mathrm{M}]_{\mathrm{DMA}}:} \\
{[\mathrm{M}]_{\text {macro-CTA }}}\end{array}$ & $\begin{array}{l}\text { Time } \\
\text { (min) }\end{array}$ & $\begin{array}{l}\text { Conv. } \\
(\%)^{a}\end{array}$ & $M_{n \text { theo }}{ }^{b}$ & $M_{n \mathrm{SEC}^{c}}$ & $\emptyset^{c}$ \\
\hline 1 & 200:1 & 5 & 13 & 12,000 & 5,600 & 1.07 \\
\hline 2 & $200: 1$ & 15 & 48 & 18,900 & 6,300 & 1.04 \\
\hline 3 & 200:1 & 30 & 76 & 24,500 & 13,900 & 1.09 \\
\hline 4 & 200:1 & 45 & 84 & 26,100 & 22,400 & 1.05 \\
\hline 5 & 200:1 & 60 & 88 & 26,900 & 24,200 & 1.06 \\
\hline 6 & 200:1 & 75 & 92 & 27,700 & 25,400 & 1.06 \\
\hline 7 & 200:1 & 90 & 93 & 27,900 & 26,200 & 1.06 \\
\hline 8 & 200:1 & 120 & 95 & 28,200 & 26,200 & 1.06 \\
\hline
\end{tabular}




\section{Synthesis of PEtPn $62-b-P_{6 M A}$}

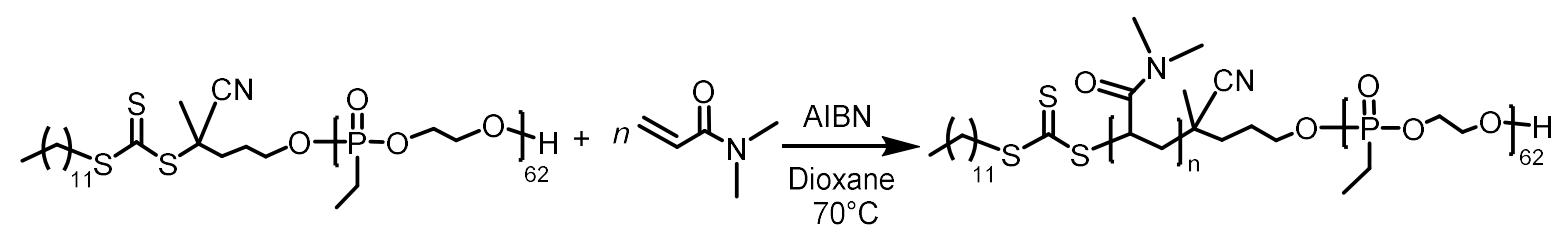

Scheme S4. Synthesis of $\operatorname{PEtPn}_{47}-b-\mathrm{PDMA}$ by RAFT polymerization.

NOTE: During the course of this work other samples of PEtPn- $b-$ PDMA were prepared and described in the main manuscript. A representative procedure for the synthesis of a PEtPn- $b-\mathrm{PDMA}$ is described.

PEtPn $_{62}$ macro-CTA (131 mg, $\left.0.01 \mathrm{mmol}, 1 \mathrm{eq}\right)$ and DMA (407 mg, $\left.4.11 \mathrm{mmol}, 213 \mathrm{eq}\right)$ were dissolved in dioxane $(0.6 \mathrm{~mL})$ in a Schlenk flask. A stock solution of AIBN $\left(10 \mathrm{mg} \mathrm{mL} \mathrm{m}^{-1}\right)$ was prepared and AIBN $(0.3$ $\mathrm{mg}, 0.002 \mathrm{mmol}, 0.1 \mathrm{eq}$ ) was added. The reaction mixture was stirred at room temperature followed by three freeze-pump-thaw cycles. The Schlenk flask was placed in a preheated oil bath at $70{ }^{\circ} \mathrm{C}$ for $1 \mathrm{~h}$. Finally, the flask was placed in liquid nitrogen until frozen and opened to air to terminate the polymerization. The crude product was purified by precipitation into cold diethyl ether $\left(-28^{\circ} \mathrm{C}\right)$ three times and drying in vacuo to yield $\mathrm{PEtPn}_{62}-b-\mathrm{PDMA}_{230}$ as a yellow glassy solid $(0.37 \mathrm{~g}, 68 \%)$.

\section{Characterization of $\operatorname{PEtPn}_{62}-b-P^{-} M_{230}$}

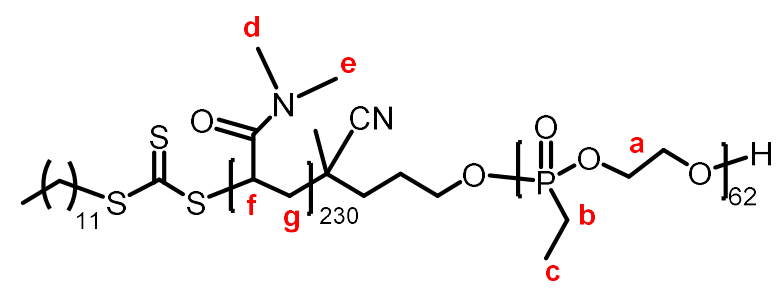

${ }^{1} \mathrm{H} \mathrm{NMR}\left(\mathrm{CDCl}_{3}\right): \delta$ (ppm) 4.25-4.18 (m, Ha, $262 \mathrm{H}$ ); 3.10-2.15 (m, Hd, He, Hf, $1964 \mathrm{H}$ ), 1.84-1.13 (m, $\mathrm{Hb}, \mathrm{Hc}, \mathrm{Hg}, 980 \mathrm{H})$. End-group ${ }^{1} \mathrm{H}$ NMR spectroscopy analysis showed $D P_{n}=230$ for DMA based on 'a' (backbone $-\mathrm{CH}_{2}-\mathrm{CH}_{2}$ ) (Fig. S7)

${ }^{31} \mathrm{P}$ NMR ( $\left.\mathrm{CDCl}_{3}\right): \delta(\mathrm{ppm}) 35.3$ (Fig. S8)

SEC: $M_{\mathrm{n}}=33,300 \mathrm{~g} / \mathrm{mol} ; \varnothing=1.08$ (Fig. S10) 


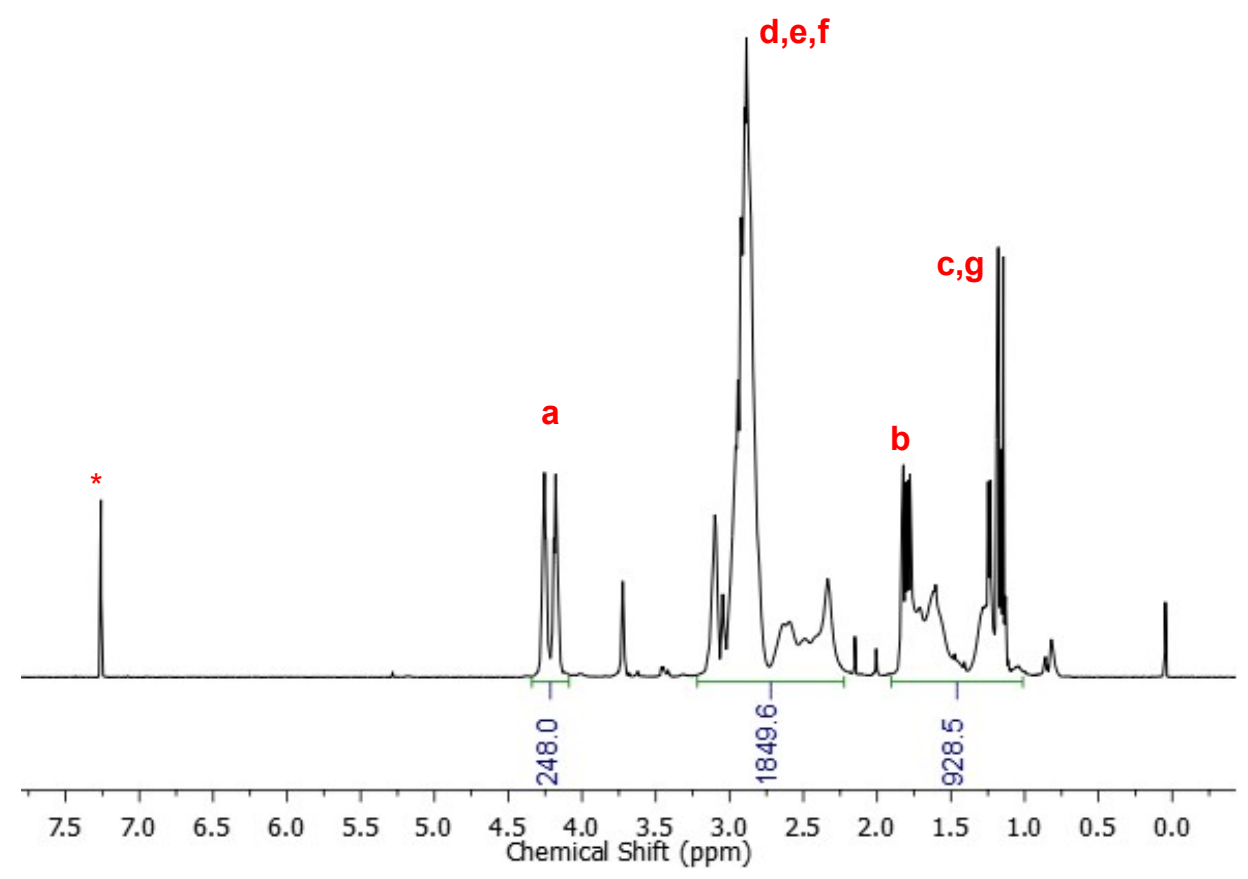

Figure S7. ${ }^{1} \mathrm{H}$ NMR $\left(400 \mathrm{MHz}, \mathrm{CDCl}_{3}\right)$ spectrum of $\mathrm{PEtPn}_{62}-b-\mathrm{PDMA}_{230}$. Deuterated solvent residual signal denote by *.

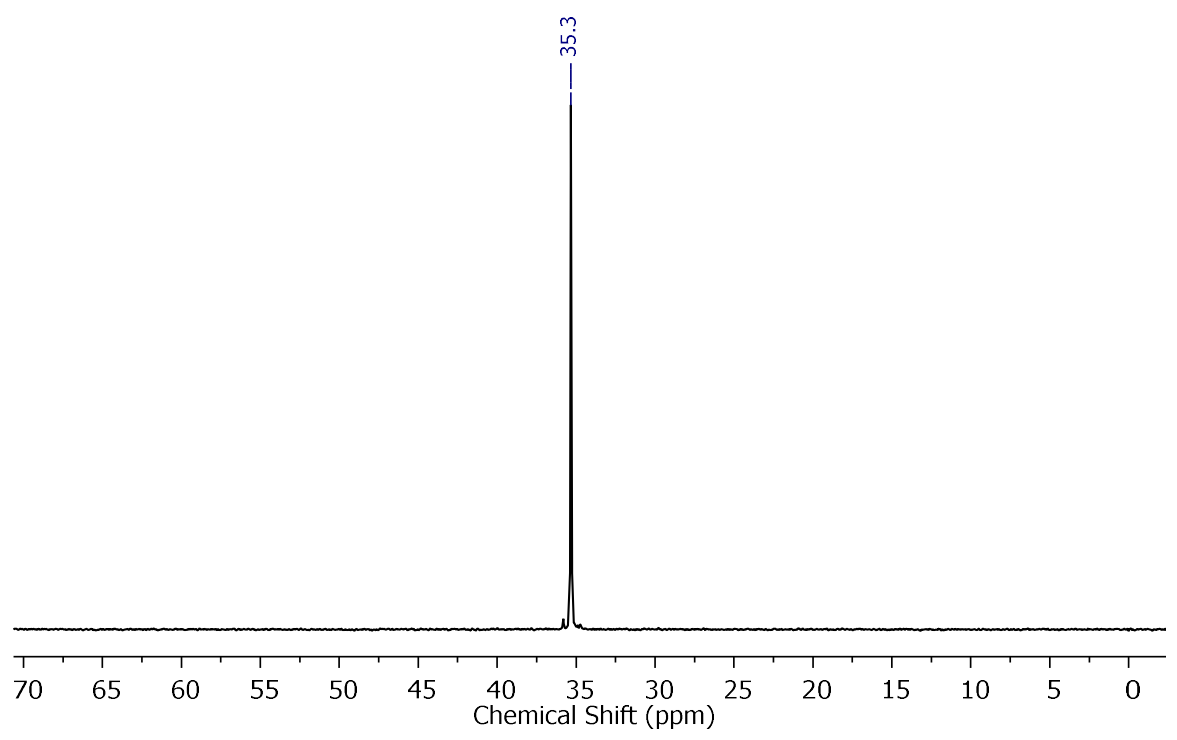

Figure S8. ${ }^{31} \mathrm{P}$ NMR $\left(162 \mathrm{MHz}, \mathrm{CDCl}_{3}\right)$ spectrum of $\mathrm{PEtPn}_{62}-b-\mathrm{PDMA}_{230}$. 


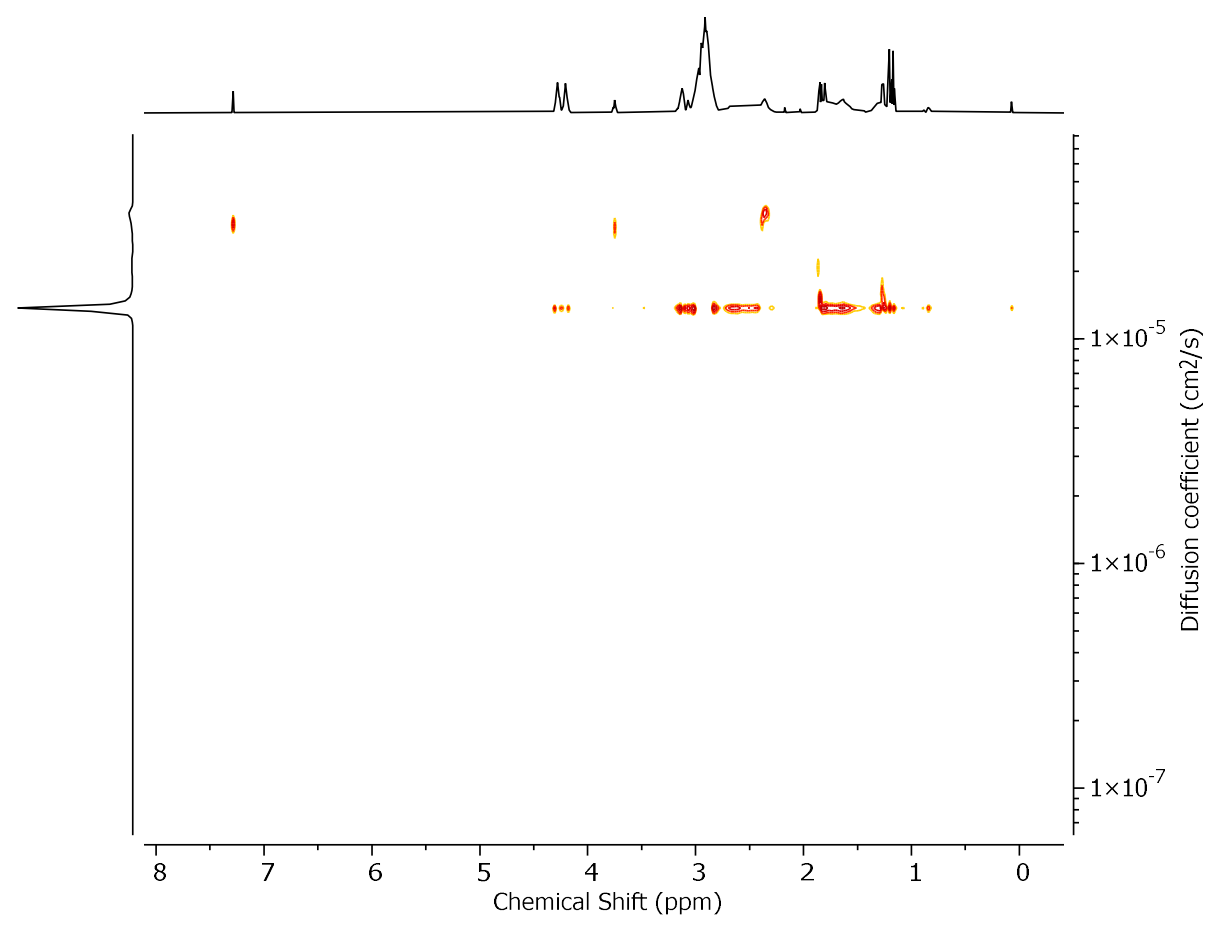

Figure S9. ${ }^{1} \mathrm{H}$ DOSY NMR $\left(600 \mathrm{MHz}, \mathrm{CDCl}_{3}\right)$ spectrum of $\mathrm{PEtPn}_{62}-b-\mathrm{PDMA}_{230}$.

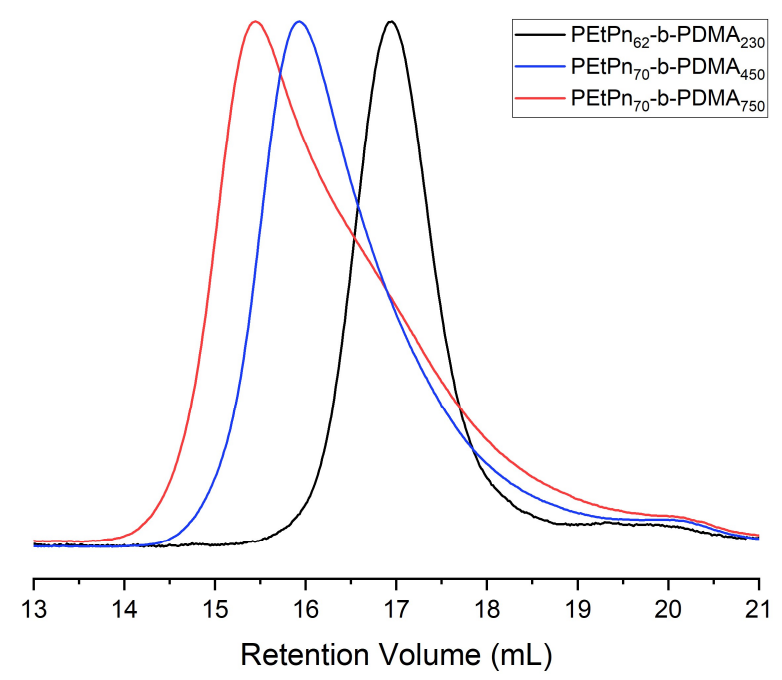

Figure S10. SEC elugrams $\left(2 \mathrm{mg} \mathrm{mL}^{-1}\right)$ (normalized RI) of $\mathrm{PEtPn}_{n}-b-\mathrm{PDMA}_{m}$ of different molar masses (measured in DMF $(0.1 \mathrm{M} \mathrm{LiCl})$ at $60^{\circ} \mathrm{C}$ ) (See from main manuscript Table 1, entry 1-3). 
Table S4. Molar mass and distribution determined by SEC for different PEtPn- $b$-PDMA block copolymers prepared via RAFT polymerization.

\begin{tabular}{|c|c|c|c|c|c|c|}
\hline Entry & $\begin{array}{c}{[\mathrm{M}]_{\mathrm{DMA}}:} \\
{[\mathrm{M}]_{\text {macro-CTA }}}\end{array}$ & $\begin{array}{c}\text { Time } \\
(\mathrm{min})\end{array}$ & $\begin{array}{c}\text { Conv. } \\
(\%)^{a}\end{array}$ & $M_{n \text { theo }}{ }^{b}$ & $M_{\mathrm{n} \mathrm{SEC}^{b}}$ & $D^{b}$ \\
\hline 1 & $300: 1$ & 60 & 87 & 30,100 & 33,300 & 1.08 \\
\hline 2 & $450: 1$ & 120 & 98 & 45,000 & 52,700 & 1.20 \\
\hline 3 & $750: 1$ & 120 & 98 & 74,700 & 56,800 & 1.39 \\
\hline
\end{tabular}

${ }^{a}\left[\left(D P_{n} * 99.13\right)+389\right]$.

${ }^{b}$ Calculated by ${ }^{1} \mathrm{H}$ NMR spectroscopy.

${ }^{c}$ Determined by SEC in DMF $(0.1 \mathrm{M} \mathrm{LiCl})$ at $60{ }^{\circ} \mathrm{C}$.

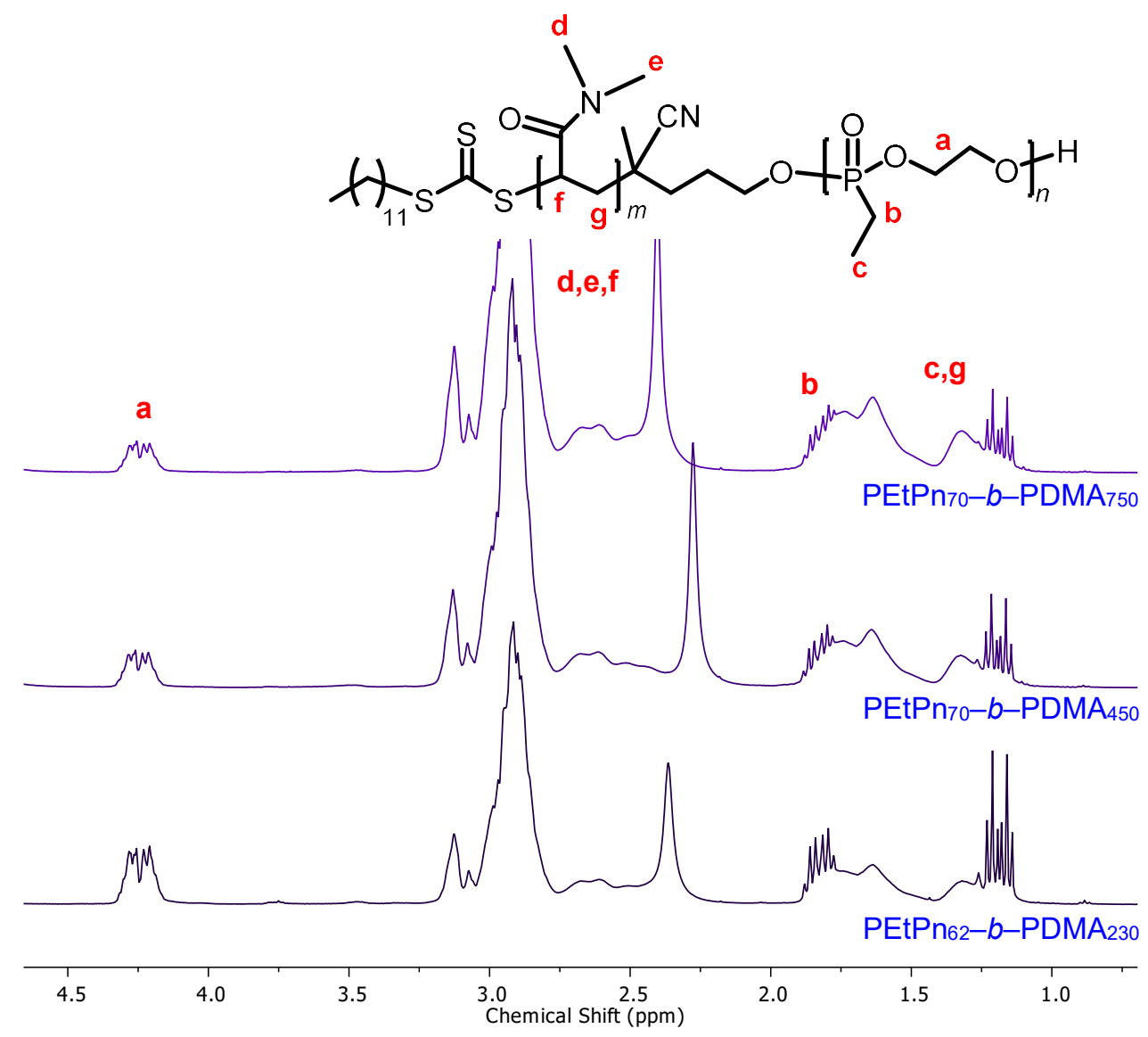

Figure S11. ${ }^{1} \mathrm{H}$ NMR $\left(400 \mathrm{MHz}, \mathrm{CDCl}_{3}\right)$ spectrum of $\mathrm{PEtPn}_{n}-b-\mathrm{PDMA}_{m}$ of different molar masses. 


\section{Kinetics of RAFT polymerization of ethyl methacrylate and PEtPn macro-CTA}

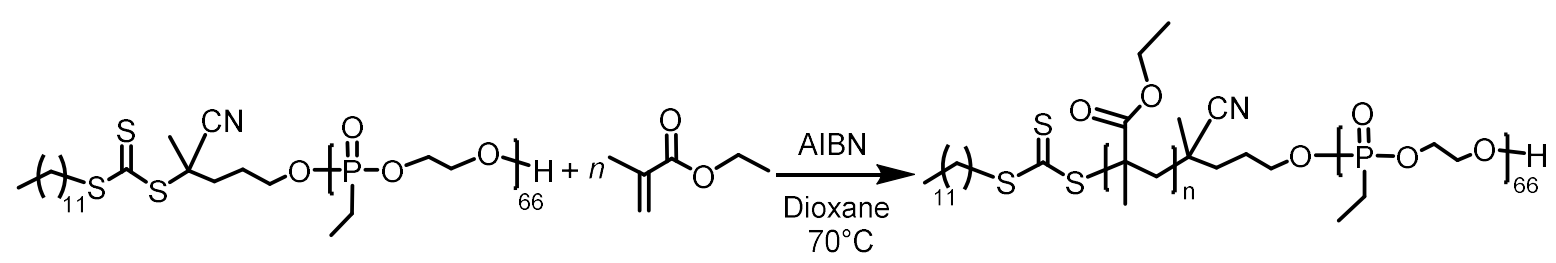

Scheme S5. Synthesis of PEtPn- $b-$ PEM by RAFT polymerization.

$\operatorname{PEtPn}_{70}$ macro-CTA (155 mg, $\left.0.01 \mathrm{mmol}, 1 \mathrm{eq}\right)$ and ethyl methacrylate (EM) (357 mg, $\left.3.13 \mathrm{mmol}, 200 \mathrm{eq}\right)$ were dissolved in dioxane $(0.78 \mathrm{~mL})$ in a Schlenk flask. A stock solution of AIBN $\left(10 \mathrm{mg} \mathrm{mL} \mathrm{m}^{-1}\right)$ was prepared and AIBN $(0.27 \mathrm{mg}, 0.001 \mathrm{mmol}, 0.1 \mathrm{eq})$ was added. The reaction mixture was stirred at room temperature followed by three freeze-pump-thaw cycles. The Schlenk flask was placed in a preheated oil bath at $70^{\circ} \mathrm{C}$. The sampling involved periodic extraction of aliquots from the reaction mixture, followed by dissolution in $\mathrm{CDCl}_{3}$, which is a good solvent for both the PEtPn-macro CTA and PEM blocks. Each sample was analyzed by ${ }^{1} \mathrm{H}$ NMR spectroscopy and SEC in DMF $(0.1 \mathrm{M} \mathrm{LiCl})$ at $60{ }^{\circ} \mathrm{C}$.

During the first two hours, the SEC trace displayed a bimodal peak which was reduced at later stages of the reaction (Fig. S12). In general, the polymer molar mass increased linearly with respect to monomer conversion (Fig. S13b) and maintained a low $\doteq$, indicative of control over the radical polymerization. A plot of $\ln \left([\mathrm{M}]_{0} /[\mathrm{M}]_{\mathrm{t}}\right)$ vs. time revealed a linear relationship up to $8 \mathrm{~h}$ (ca. $79 \%$ conversion), indicating pseudo-first-order kinetics (Fig. S13a). 
Table S5. Kinetics of the synthesis of PEtPn- $b$-PEM block copolymer prepared via RAFT polymerization.

\begin{tabular}{|c|c|c|c|c|c|c|}
\hline Entry & $\begin{array}{c}{[\mathrm{M}]_{\mathrm{EM}}:} \\
{[\mathrm{M}]_{\text {macro-CTA }}}\end{array}$ & $\begin{array}{c}\text { Time } \\
(\mathrm{min})\end{array}$ & $\begin{array}{c}\text { Conv. } \\
(\%)^{a}\end{array}$ & $M_{\mathrm{n} \text { theo }}{ }^{b}$ & $M_{\mathrm{n} \mathrm{SEC}}{ }^{c}$ & $\Xi^{c}$ \\
\hline 1 & $200: 1$ & 60 & 20 & 13,900 & 9,900 & 1.22 \\
\hline 2 & $200: 1$ & 120 & 29 & 16,000 & 12,100 & 1.21 \\
\hline 3 & $200: 1$ & 180 & 42 & 19,000 & 17,800 & 1.07 \\
\hline 4 & $200: 1$ & 240 & 51 & 21,000 & 19,200 & 1.07 \\
\hline 5 & $200: 1$ & 300 & 59 & 22,800 & 20,300 & 1.07 \\
\hline 6 & $200: 1$ & 360 & 65 & 24,200 & 21,900 & 1.06 \\
\hline 7 & $200: 1$ & 420 & 70 & 25,300 & 22,600 & 1.07 \\
\hline 8 & $203: 1$ & 480 & 79 & 27,400 & 24,000 & 1.07 \\
\hline
\end{tabular}

${ }^{a}$ Calculated by ${ }^{1} \mathrm{H}$ NMR spectroscopy.

${ }^{b}\left[\left(\left(\right.\right.\right.$ conversion $\left.\left.\left.[\mathrm{M}]_{\mathrm{EM}} / 100 *[\mathrm{M}]_{\mathrm{EM}}:[\mathrm{M}]_{\text {macro-CTA }}\right) * 114.14\right)+9370\right]$.

${ }^{c}$ Determined by SEC in DMF $(0.1 \mathrm{M} \mathrm{LiCl})$ at $60^{\circ} \mathrm{C}$.

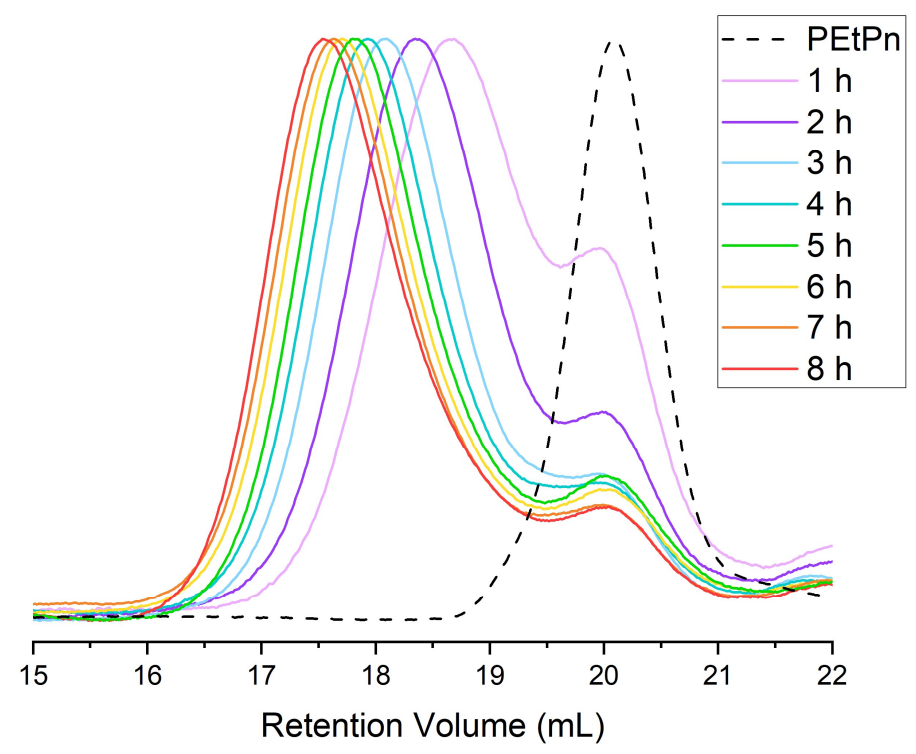

Fig S12. SEC elugrams $\left(2 \mathrm{mg} \mathrm{mL}^{-1}\right)$ (normalized RI) of the kinetics for PEtPn- $b-\mathrm{PEM}$ terminated at different reaction times (measured in $\operatorname{DMF}(0.1 \mathrm{M} \mathrm{LiCl})$ at $\left.60^{\circ} \mathrm{C}\right)$. 

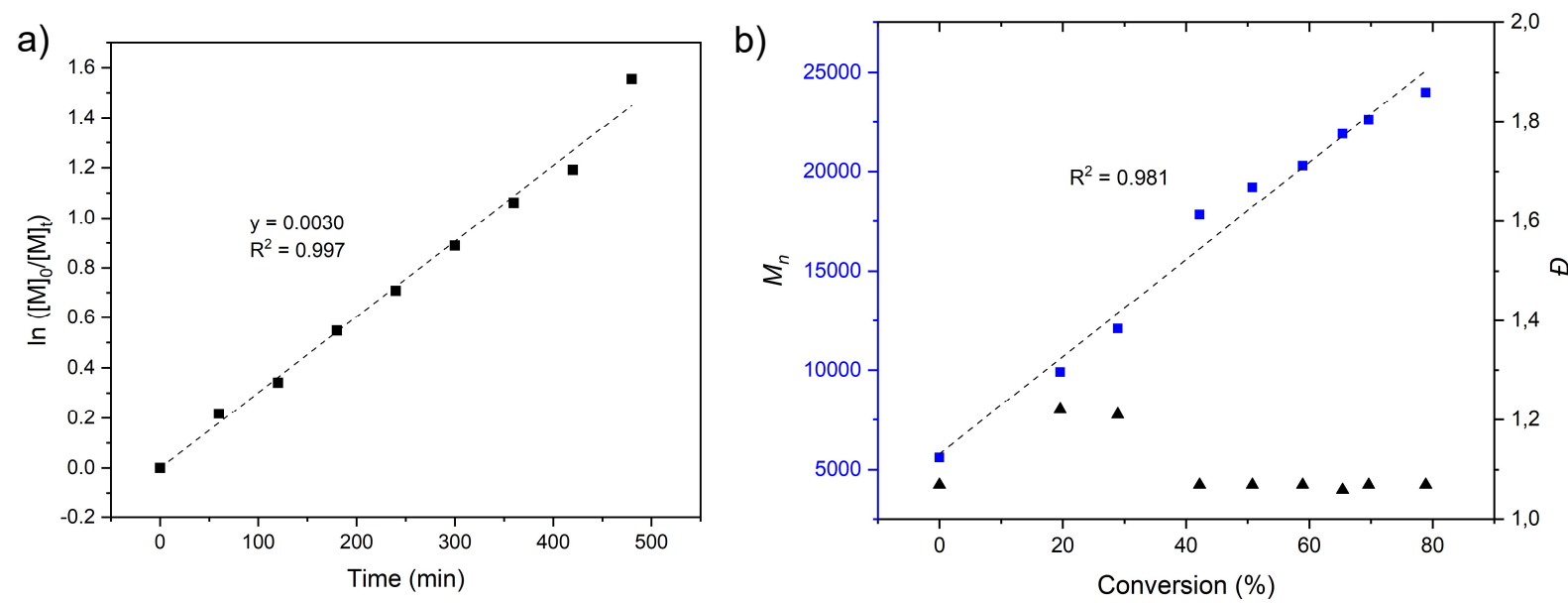

Fig S13. a) Kinetic studies of RAFT polymerization of PEtPn macro-CTA and EM. Plot of $\ln \left([\mathrm{M}]_{0} /[\mathrm{M}]_{\mathrm{t}}\right) \mathrm{vs}$ time and c) Plot on $M_{\mathrm{n}}$ and $Ð$ vs monomer conversion, obtained by a combination of SEC in DMF $(0.1 \mathrm{M}$ $\mathrm{LiCl})$ at $60^{\circ} \mathrm{C}$ and ${ }^{1} \mathrm{H}$ NMR spectroscopy analysis.

\section{Synthesis of PEtPn 6 -b-PEM 170}

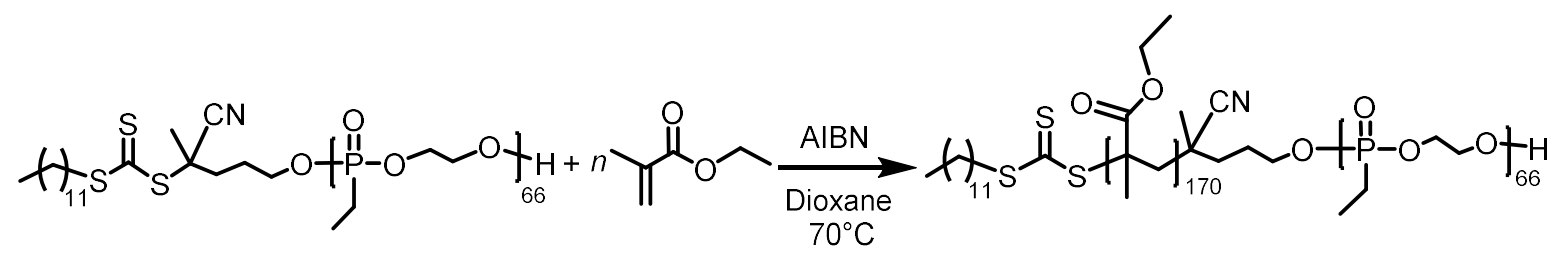

Scheme S6. Synthesis of $\mathrm{PEtPn}_{66}-b-\mathrm{PEM}_{170}$ by RAFT polymerization.

PEtPn $_{66}$ macro-CTA (51 mg, $\left.0.005 \mathrm{mmol}, 1 \mathrm{eq}\right)$ and EM (125 mg, $\left.1.09 \mathrm{mmol}, 200 \mathrm{eq}\right)$ were dissolved in dioxane $(0.3 \mathrm{~mL})$ in a Schlenk flask. A stock solution of AIBN $\left(10 \mathrm{mg} \mathrm{mL}^{-1}\right)$ was prepared and AIBN $(0.09$ $\mathrm{mg}, 0.0005 \mathrm{mmol}, 0.1 \mathrm{eq}$ ) was added. The reaction mixture was stirred at room temperature followed by three freeze-pump-thaw cycles. The Schlenk flask was placed in a preheated oil bath at $70{ }^{\circ} \mathrm{C}$ for $6 \mathrm{~h}$. Finally, the flask was placed in liquid nitrogen until frozen and opened to air to terminate the polymerization. The crude product was purified by precipitation into cold petroleum ether $\left(-28{ }^{\circ} \mathrm{C}\right)$ three times and drying in vacuo to yield $\mathrm{PEtPn}_{66}-b-\mathrm{PEM}_{170}$ as a slightly yellow solid (0.10 g, $\left.57 \%\right)$. 


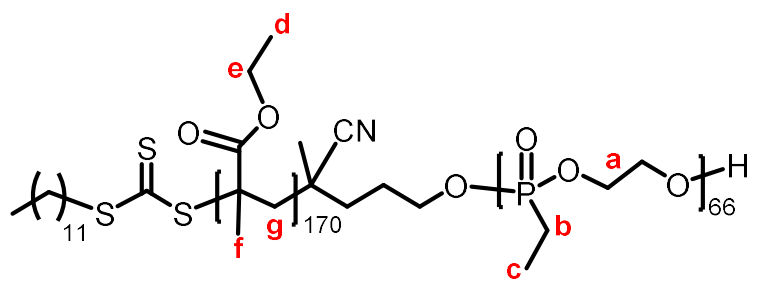

${ }^{1} \mathrm{H}$ NMR $\left(\mathrm{CDCl}_{3}\right): \delta$ (ppm) 4.23-4.20 (m, Ha, $\left.264 \mathrm{H}\right) ; 2.55$ (m, He, $\left.341 \mathrm{H}\right) ; 2.01-1.74$ (m, Hb, Hg, $\left.472 \mathrm{H}\right)$, 1.32-1.24 (m, Hd, 555 H); 1.23-1.17 (m, Hc, $210 \mathrm{H}) ; 1.08-1.01$ and 0.93-0.84 (m, Hf, 512H). End-group ${ }^{1} \mathrm{H}$ NMR spectroscopy analysis showed $D P_{n}=170$ for EM based on 'a' (backbone $-\mathrm{CH}_{2}-\mathrm{CH}_{2}$ ) (Fig. S14)

${ }^{31} \mathrm{P}$ NMR $\left(\mathrm{CDCl}_{3}\right): \delta(\mathrm{ppm}) 35.2$ (Fig. S15)

SEC: $M_{\mathrm{n}}=21,800 \mathrm{~g} / \mathrm{mol} ; \varnothing=1.08$ (Fig. S17)

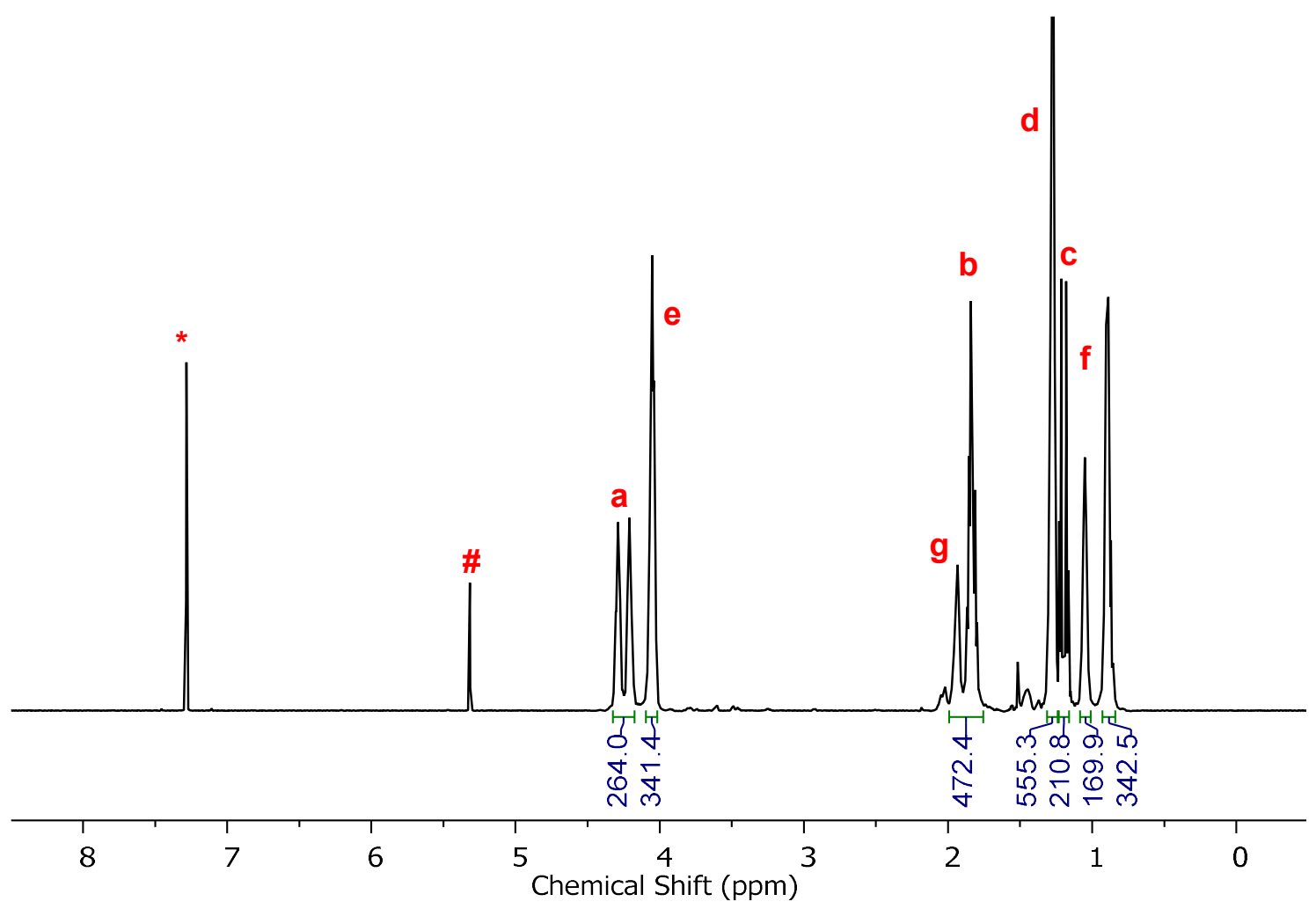

Figure S14. ${ }^{1} \mathrm{H} \mathrm{NMR}\left(400 \mathrm{MHz}, \mathrm{CDCl}_{3}\right)$ spectrum of $\mathrm{PEtPn}_{66}-b-\mathrm{PEM}_{170}$. Deuterated solvent residual signal denote by * and $\mathrm{CH}_{2} \mathrm{Cl}_{2}$ residual signal denote by \#. 


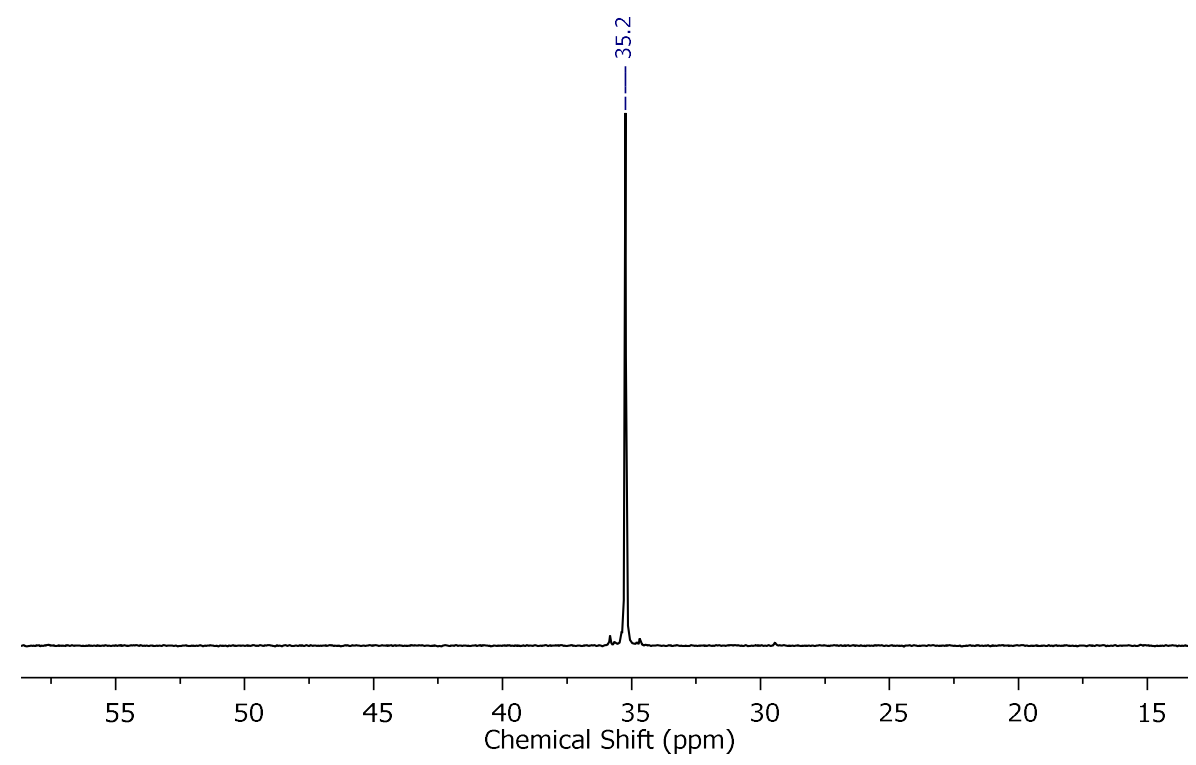

Figure S15. ${ }^{31} \mathrm{P}$ NMR $\left(162 \mathrm{MHz}, \mathrm{CDCl}_{3}\right)$ spectrum of $\mathrm{PEtPn}_{66}-b-\mathrm{PEM}_{170}$

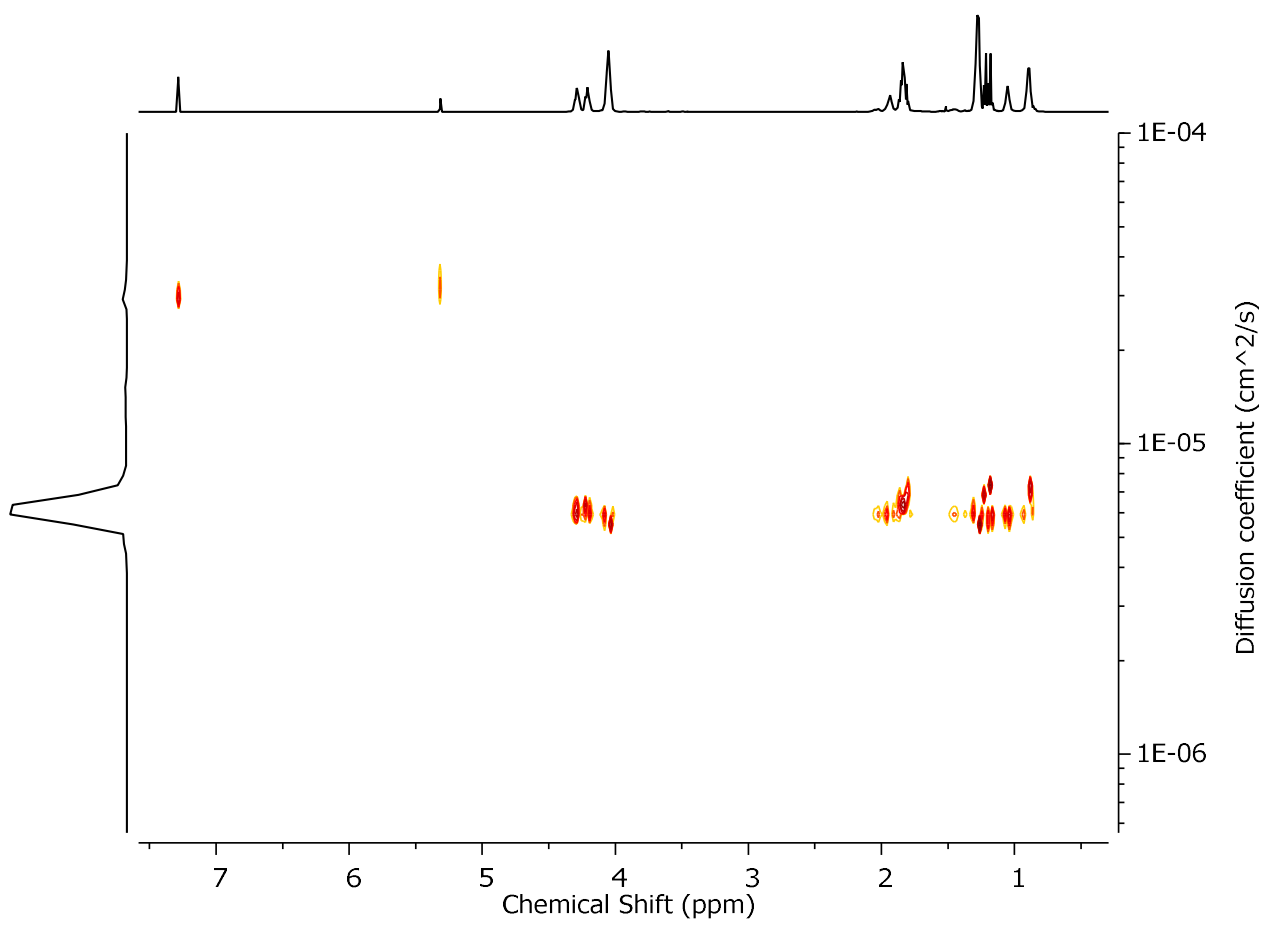

Figure S16. ${ }^{1} \mathrm{H}$ DOSY NMR (600 MHz, $\left.\mathrm{CDCl}_{3}\right)$ spectrum of $\mathrm{PEtPn}_{66}-b-\mathrm{PEM}_{170}$. 


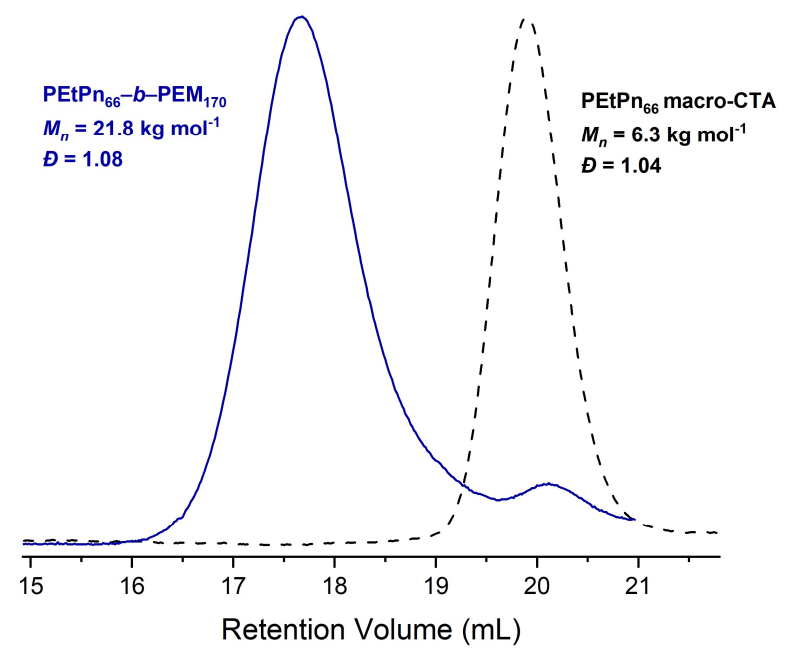

Figure S17. SEC elugrams $\left(2 \mathrm{mg} \mathrm{mL}^{-1}\right)$ (normalized RI) of isolated $\mathrm{PEtPn}_{66}-b-\mathrm{PEM}_{170}$ (blue, $D=1.08$ ) and PEtPn $_{66}$ macro-CTA (black, $Ð=1.04$ ) (measured in DMF $(0.1 \mathrm{M} \mathrm{LiCl})$ at $60^{\circ} \mathrm{C}$ ).

\section{Synthesis of PEtPn $66-b-P t B u A_{226}$}

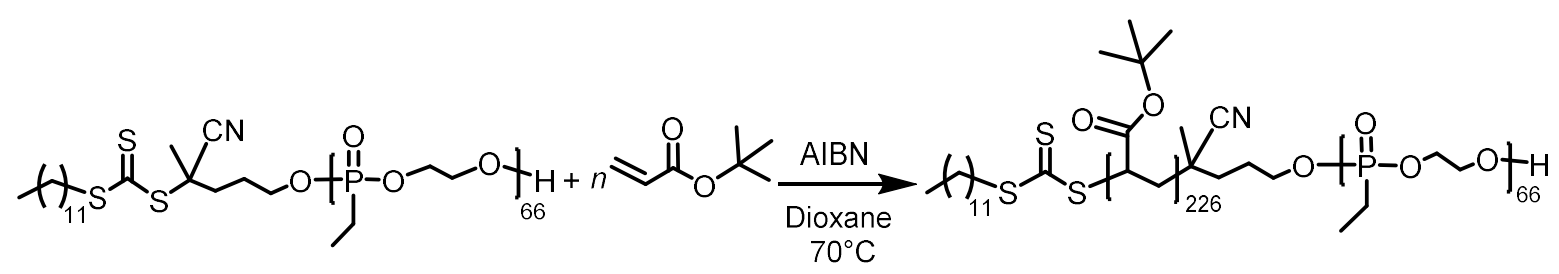

Scheme S7. Synthesis of $\mathrm{PEtPn}_{66}-b-\mathrm{P} t \mathrm{BuA}_{226}$ by RAFT polymerization.

PEtPn $_{66}$ macro-CTA (52 mg, 0.005 mmol, 1 eq) and tert-butyl acrylate ( $\left.t \mathrm{BuA}\right)(125 \mathrm{mg}, 1.09 \mathrm{mmol}, 200$ eq) were dissolved in dioxane $(0.3 \mathrm{~mL})$ in a Schlenk flask. A stock solution of AIBN $\left(10 \mathrm{mg} \mathrm{mL}^{-1}\right)$ was prepared and AIBN (0.09 mg, $0.0005 \mathrm{mmol}, 0.1 \mathrm{eq})$ was added. The reaction mixture was stirred at room temperature followed by three freeze-pump-thaw cycles. The Schlenk flask was placed in a preheated oil bath at $70{ }^{\circ} \mathrm{C}$ for $16 \mathrm{~h}$. Finally, the flask was placed in liquid nitrogen until frozen and opened to air to terminate the polymerization. The crude product was purified by precipitation into water three times and drying in vacuo to yield $\mathrm{PEtPn}_{62}-b-\mathrm{P} t \mathrm{BuA}_{210}$ as a light yellow solid (0.06 g, $33 \%$ ). 


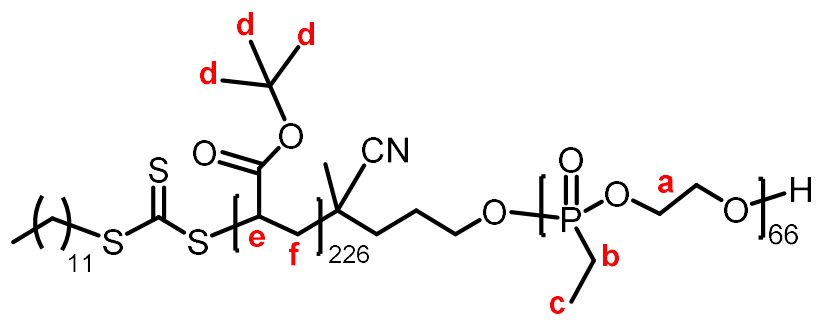

${ }^{1} \mathrm{H}$ NMR $\left(\mathrm{CDCl}_{3}\right): \delta(\mathrm{ppm})$ 4.29-4.21 (m, Ha, $\left.248 \mathrm{H}\right) ; 2.37-2.16(\mathrm{~m}, \mathrm{He}, 426 \mathrm{H}) ; 1.87-1.79(\mathrm{~m}, \mathrm{Hb}), 1.50-$ 1.21 (s, Hd, Hf); 1.23-1.17 (m, Hc). End-group ${ }^{1} \mathrm{H}$ NMR spectroscopy analysis showed $D P_{n}=226$. is based on 'a' (backbone $-\mathrm{CH}_{2}-\mathrm{CH}_{2}$ ) (Fig. S18).

${ }^{31} \mathrm{P} \mathrm{NMR}\left(\mathrm{CDCl}_{3}\right): \delta(\mathrm{ppm}) 35.2$ (Fig. S19).

SEC: $M_{\mathrm{n}}=29,700 \mathrm{~g} / \mathrm{mol} ; \quad D=1.12$ (Fig. S21).

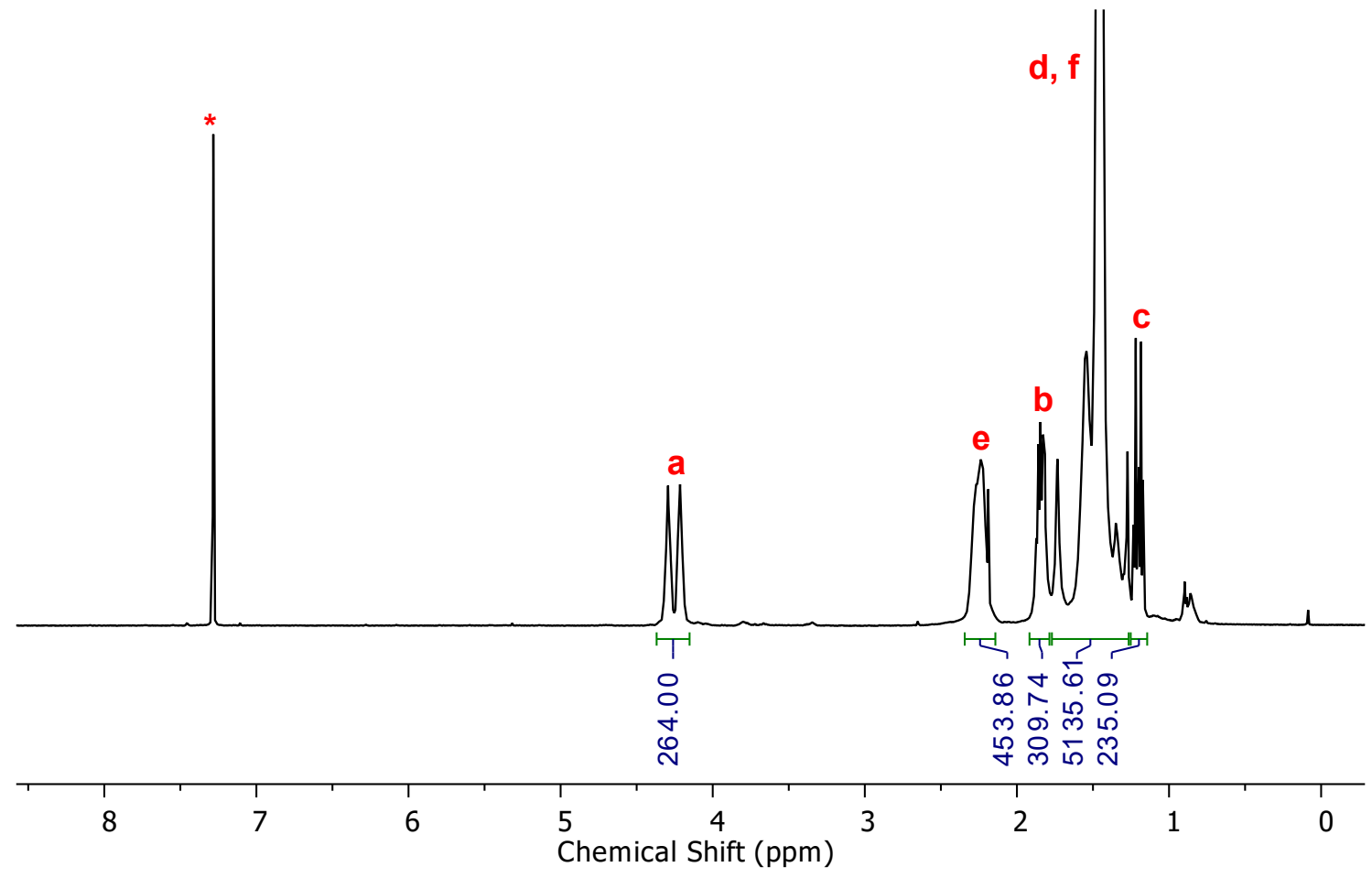

Figure S18. ${ }^{1} \mathrm{H}$ NMR $\left(400 \mathrm{MHz}, \mathrm{CDCl}_{3}\right)$ spectrum of $\mathrm{PEtPn}_{66}-b-\mathrm{P} \mathrm{BuA}_{226}$. Deuterated solvent residual signal denote by *. 


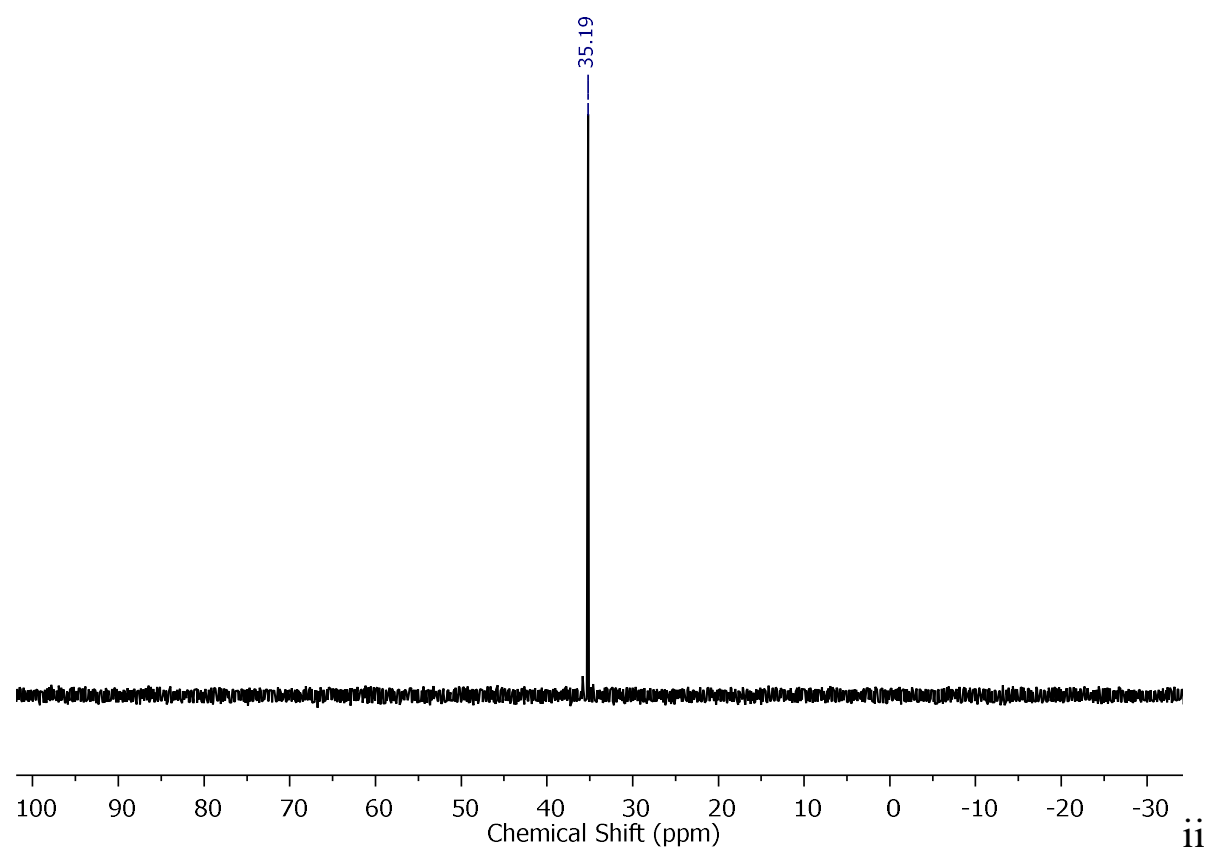

Figure S19. ${ }^{31} \mathrm{P}$ NMR $\left(162 \mathrm{MHz}, \mathrm{CDCl}_{3}\right)$ spectrum of $\mathrm{PEtPn}_{66}-b-\mathrm{P} t \mathrm{BuA}_{226}$.

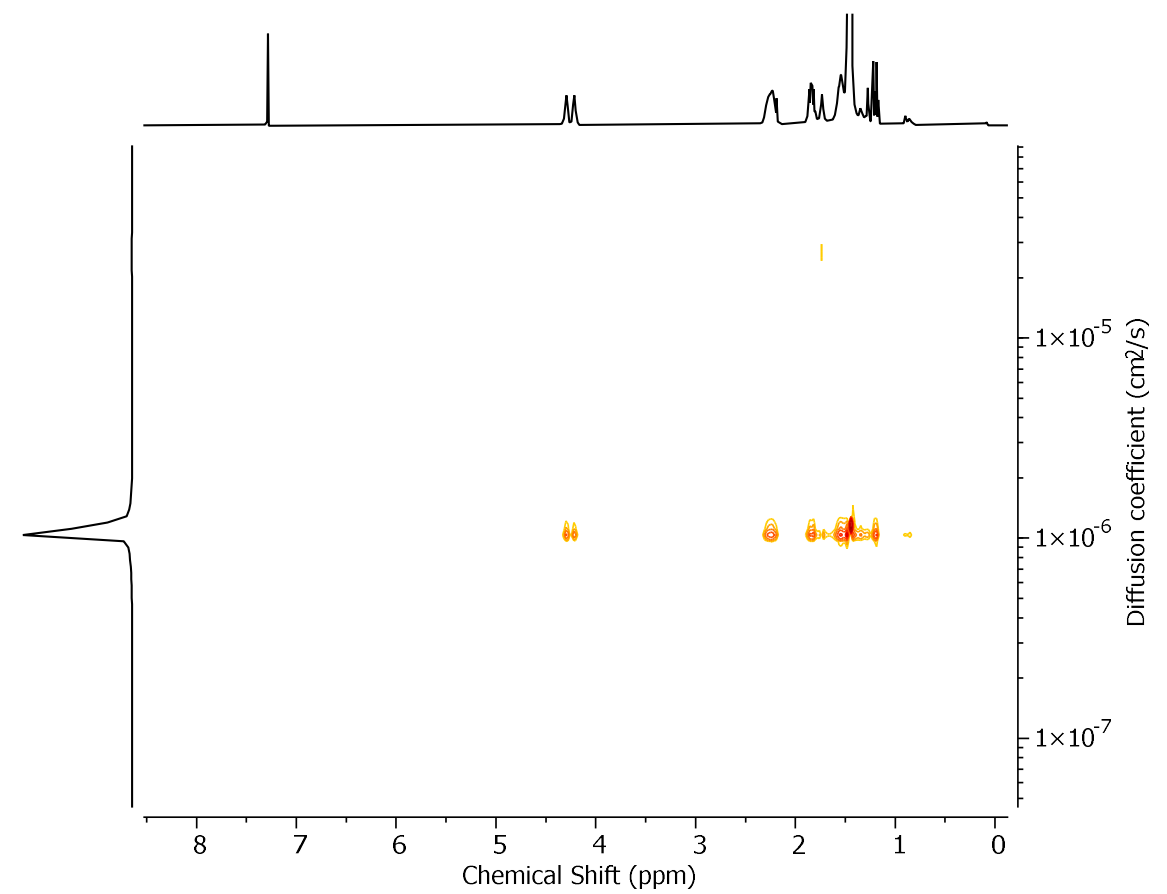

Figure S20. ${ }^{1} \mathrm{H}$ DOSY NMR (600 MHz, $\left.\mathrm{CDCl}_{3}\right)$ spectrum of $\mathrm{PEtPn}_{66}-b-\mathrm{P} t \mathrm{BuA}_{226}$. 


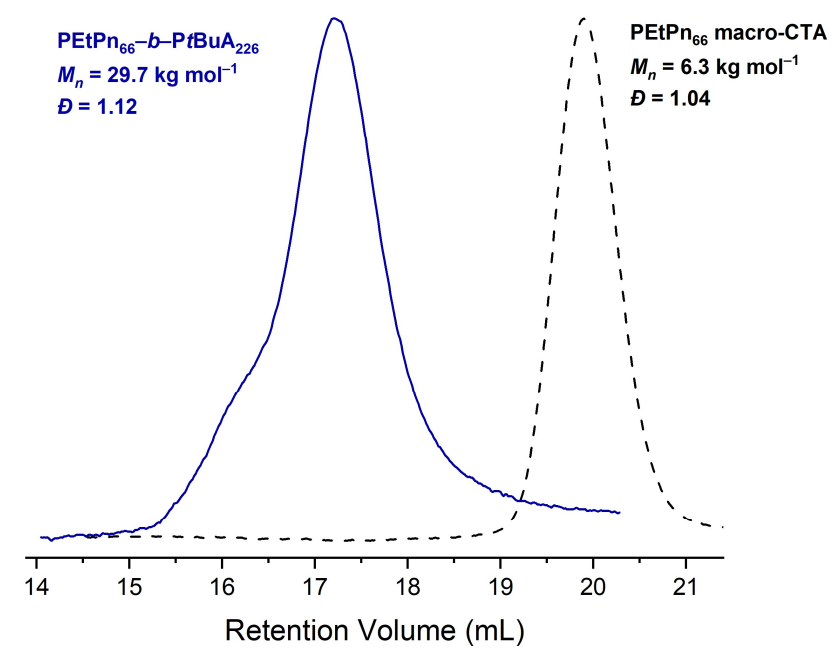

Figure S21. SEC elugrams $\left(2 \mathrm{mg} \mathrm{mL}^{-1}\right.$ ) (normalized RI) of isolated $\mathrm{PEtPn}_{66}-b-\mathrm{P} t \mathrm{BuA}_{226}$ (blue, $D=1.12$ ) and PEtPn 66 macro-CTA (black, $\oslash=1.04$ ) (measured in DMF $(0.1 \mathrm{M} \mathrm{LiCl})$ at $60{ }^{\circ} \mathrm{C}$ ).

\section{Synthesis of PEtPn ${ }_{66}-b-P_{D M A E M A} 8$}

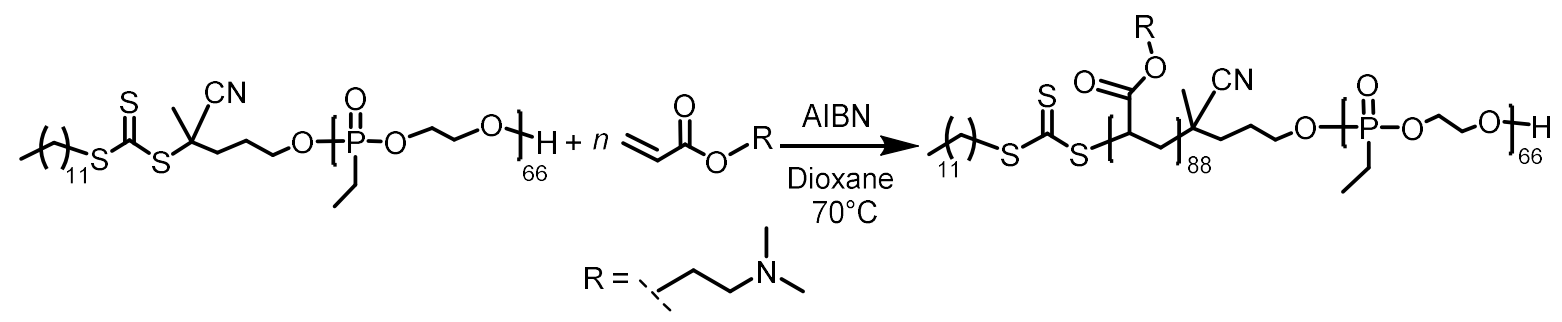

Scheme S8. Synthesis of $\mathrm{PEtPn}_{66}-b-\mathrm{PDMAEMA}_{88}$ by RAFT polymerization.

PEtPn $_{66}$ macro-CTA (50 mg, $\left.0.005 \mathrm{mmol}, 1 \mathrm{eq}\right)$ and 2-(dimethylamino)ethyl acrylate (DMAEMA) (168 $\mathrm{mg}, 1.17 \mathrm{mmol}, 218 \mathrm{eq})$ were dissolved in dioxane $(0.3 \mathrm{~mL})$ in a Schlenk flask. A stock solution of AIBN $\left(10 \mathrm{mg} \mathrm{mL}^{-1}\right)$ was prepared and AIBN $(0.09 \mathrm{mg}, 0.0005 \mathrm{mmol}, 0.1 \mathrm{eq})$ was added. The reaction mixture was stirred at room temperature followed by three freeze-pump-thaw cycles. The Schlenk flask was placed in a preheated oil bath at $70{ }^{\circ} \mathrm{C}$ and stopped at different times. Finally, the flask was placed in liquid nitrogen until frozen and opened to air to terminate the polymerization. The crude product was purified by precipitation into cold petroleum ether $\left(-28{ }^{\circ} \mathrm{C}\right)$ three times and drying in vacuo to yield $\mathrm{PEtPn}_{66}-b_{-}$ PDMAEMA 88 as a light yellow, sticky liquid $(0.079 \mathrm{~g}, 36 \%)$. 


\section{Characterization of PEtPn $66-b-P D M A E M A_{130}$}

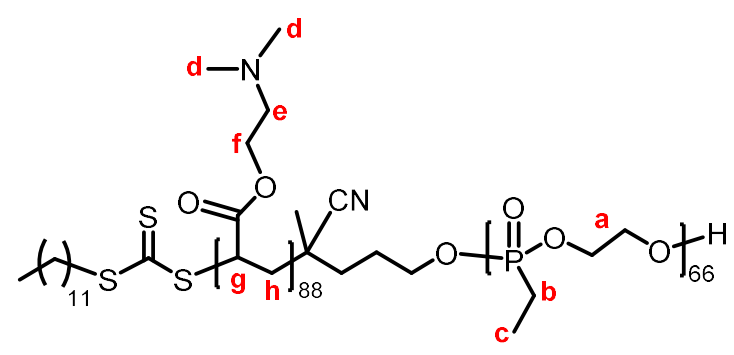

${ }^{1} \mathrm{H} \mathrm{NMR}\left(\mathrm{CDCl}_{3}\right): \delta(\mathrm{ppm})$ 4.28-4.11 (m, Ha, Hf, $522 \mathrm{H}$ ); 2.55 (s, He, $\left.260 \mathrm{H}\right) ; 2.42-2.27$ (m, Hd, Hg, 903 $\mathrm{H}), 1.98-1.88$ and 1.76-1.34 (m, Hh, $264 \mathrm{H}) ; 1.86-1.79$ (m, Hb, $135 \mathrm{H} \mathrm{);} \mathrm{1.22-1.16} \mathrm{(m,} \mathrm{Hc,} \mathrm{198H).}{ }^{1} \mathrm{H}$ integration. End-group ${ }^{1} \mathrm{H}$ NMR spectroscopy analysis showed $D P_{n}=88$ for EM is based on 'c' (sidechain $-\mathrm{CH}_{3}$ ) (Fig. S22).

${ }^{31} \mathrm{P} \mathrm{NMR}\left(\mathrm{CDCl}_{3}\right): \delta(\mathrm{ppm}) 35.3$ (Fig. S23).

SEC: $M_{n}=13,500 \mathrm{~g} / \mathrm{mol} ; \varnothing=1.28$ (Fig. S25).

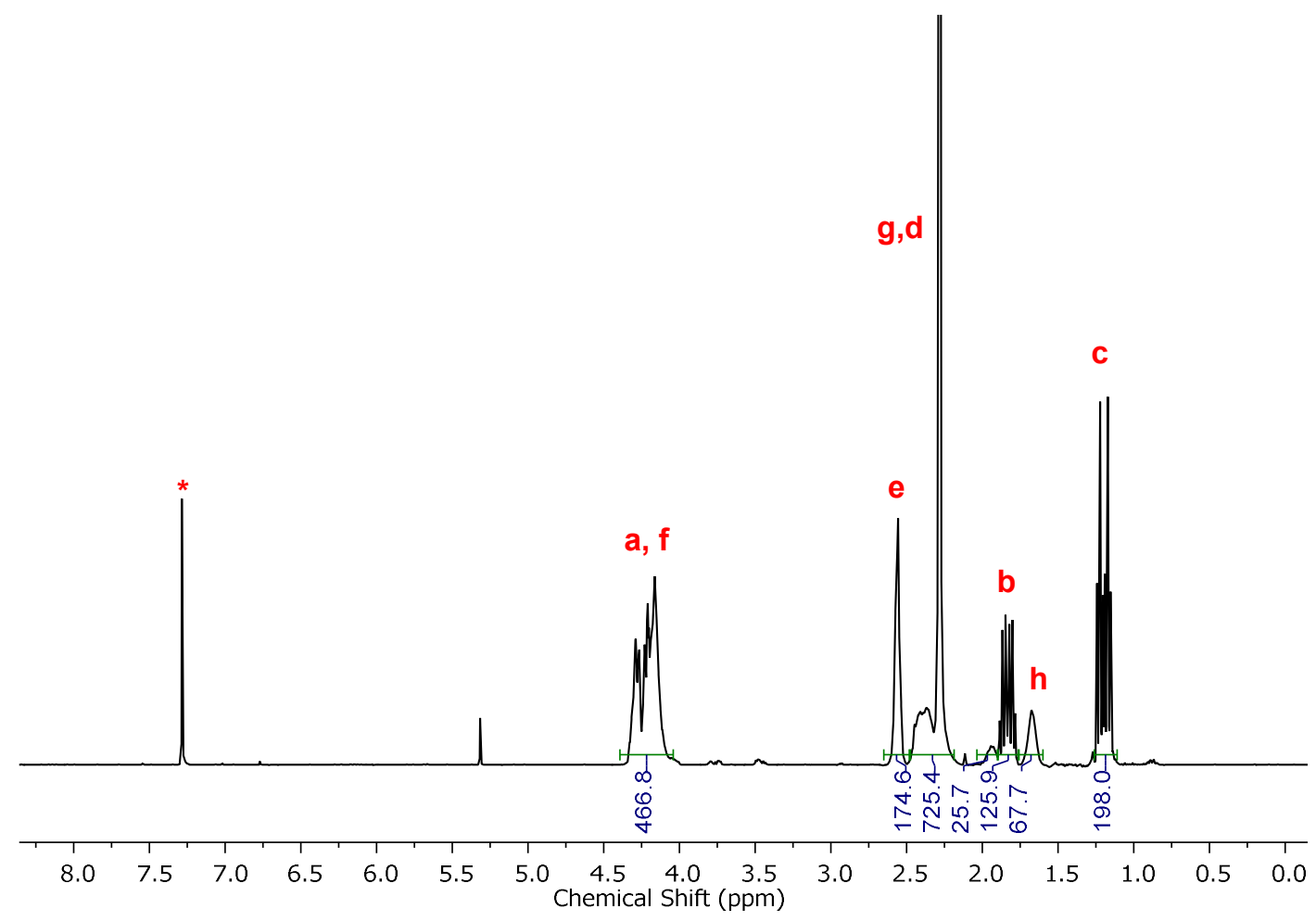

Figure S22. ${ }^{1} \mathrm{H}$ NMR $\left(400 \mathrm{MHz}, \mathrm{CDCl}_{3}\right.$ ) spectrum of isolated $\mathrm{PEtPn}_{66}-b-\mathrm{PDMAEMA}_{88}$ quenched after $6 \mathrm{~h}$ (ca. $52 \%$ conversion). Deuterated solvent residual signal denote by *. 


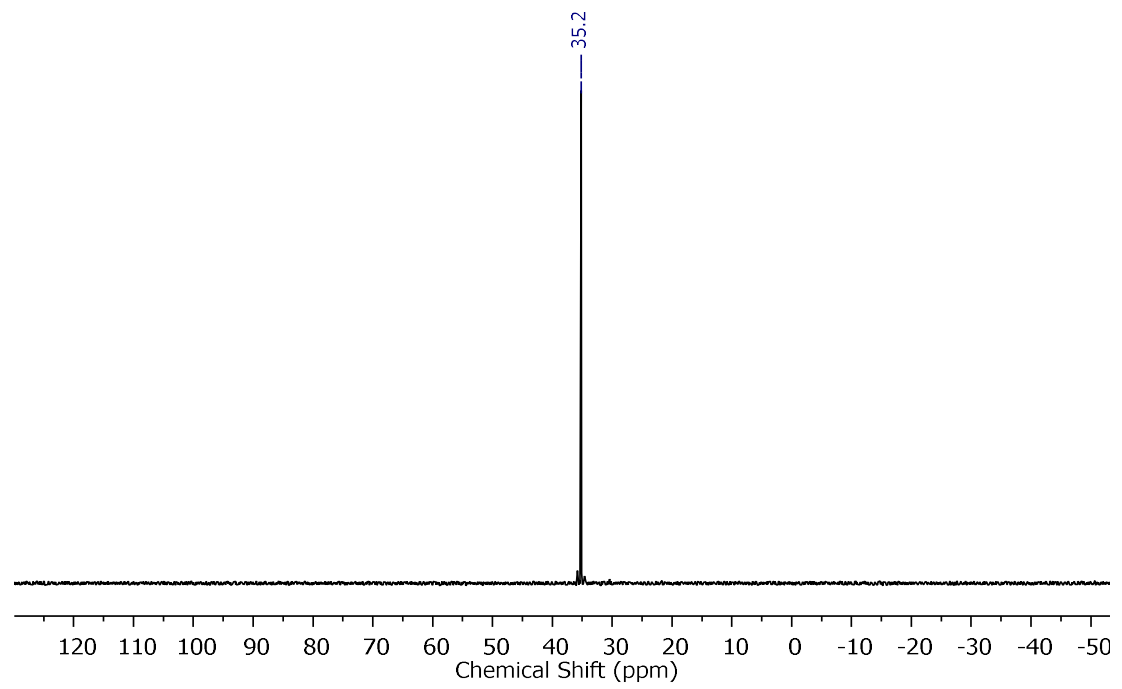

Figure S23. ${ }^{31} \mathrm{P}$ NMR $\left(162 \mathrm{MHz}, \mathrm{CDCl}_{3}\right)$ spectrum of $\mathrm{PEtPn}_{66}-b-\mathrm{PDMAEMA}_{88}$.

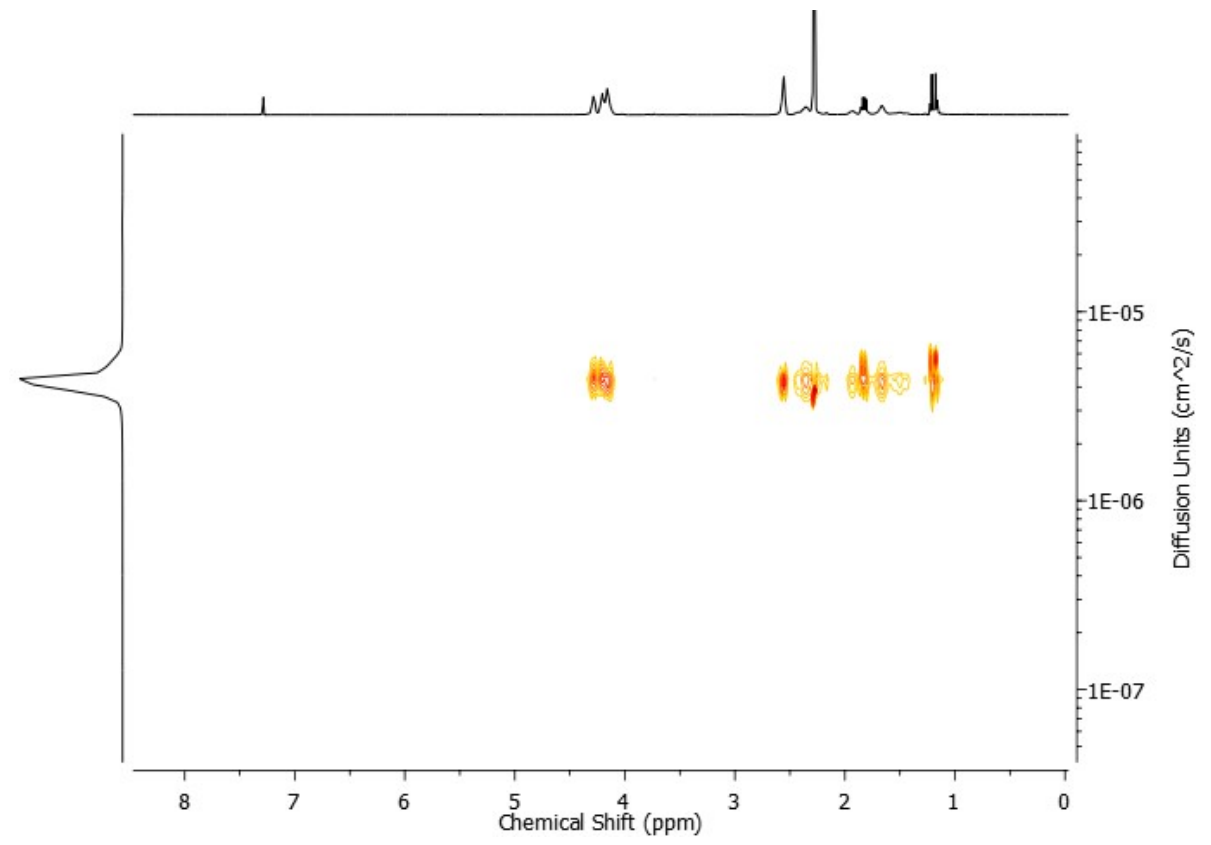

Figure S24. ${ }^{1} \mathrm{H}$ DOSY NMR $\left(600 \mathrm{MHz}, \mathrm{CDCl}_{3}\right)$ spectrum of $\mathrm{PEtPn}_{66}-b-\mathrm{PDMAEMA}_{88}$. 


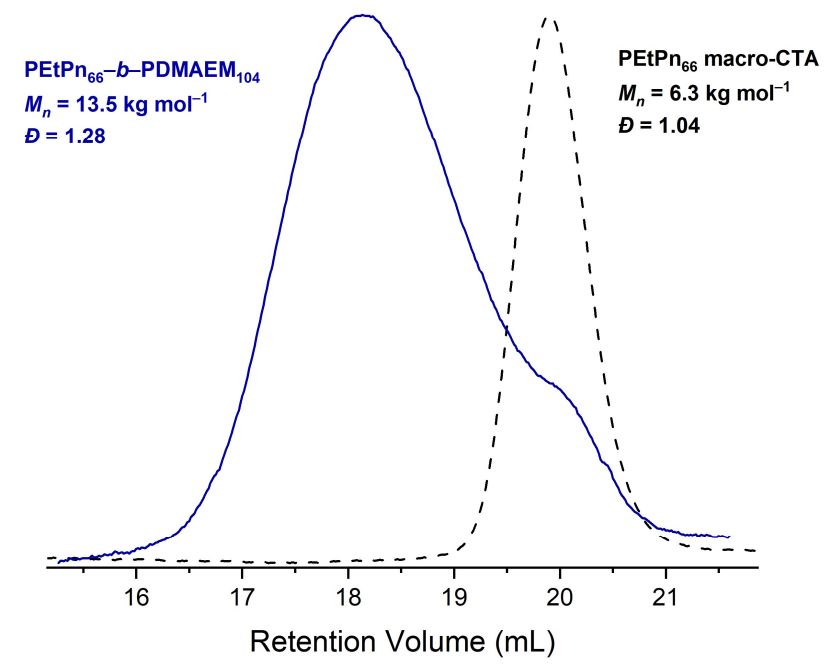

Figure S25. SEC elugrams $\left(2 \mathrm{mg} \mathrm{mL}^{-1}\right)$ (normalized RI) of isolated PEtPn $66-b-\mathrm{PDMAEMA}_{88}$ (blue, $D=$ 1.28) quenched after $6 \mathrm{~h}$ (ca. $52 \%$ conversion) and $\operatorname{PEtPn}_{66}$ macro-CTA (black, $D=1.04$ ) (measured in $\operatorname{DMF}(0.1 \mathrm{M} \mathrm{LiCl})$ at $\left.60^{\circ} \mathrm{C}\right)$.<smiles>CCP(C)(=O)OCCCCC(C)(C)CC(SC(=S)Sc1ccccc1)C(=O)OCCN(C)C</smiles>

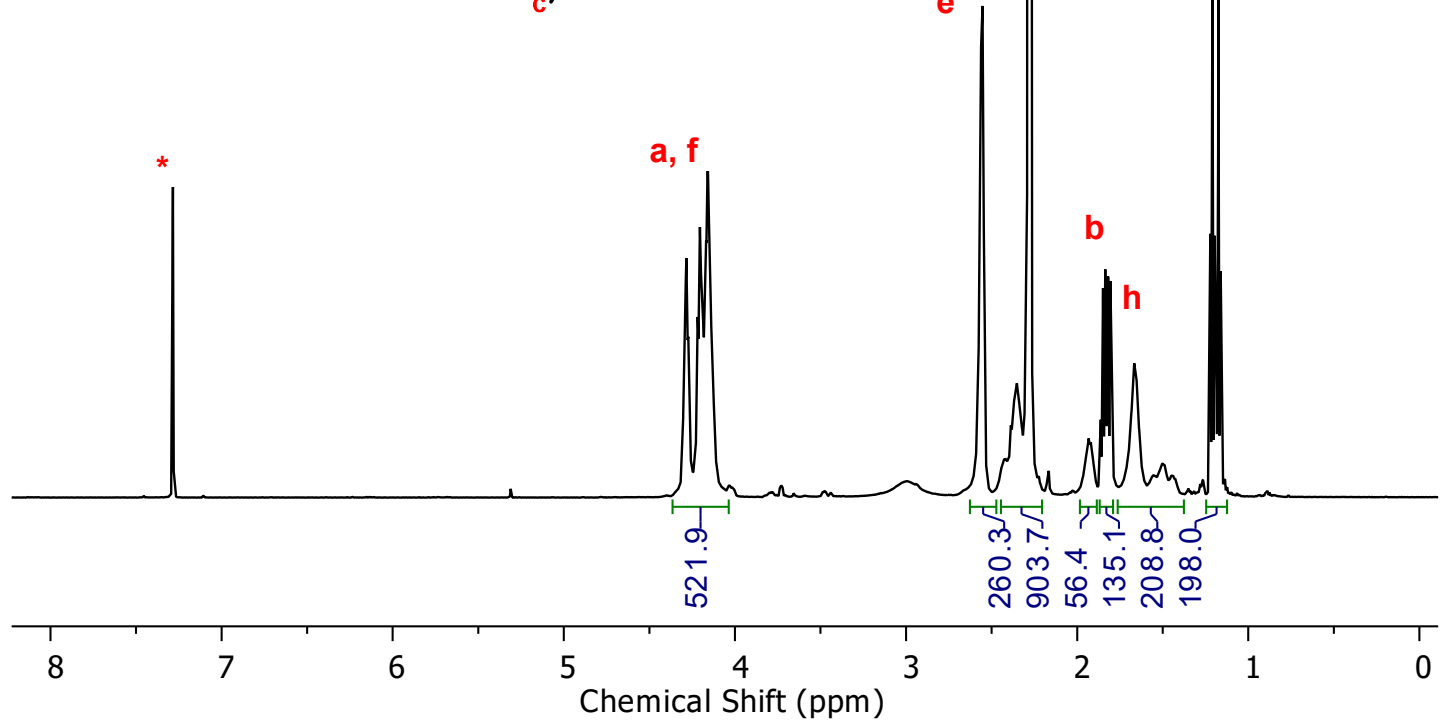

Figure S26. ${ }^{1} \mathrm{H}$ NMR $\left(400 \mathrm{MHz}, \mathrm{CDCl}_{3}\right)$ spectrum of isolated $\mathrm{PEtPn}_{66}-b-\mathrm{PDMAEMA}_{130}$ quenched after 24 h (ca. $90 \%$ conversion). Deuterated solvent residual signal denote by *. 


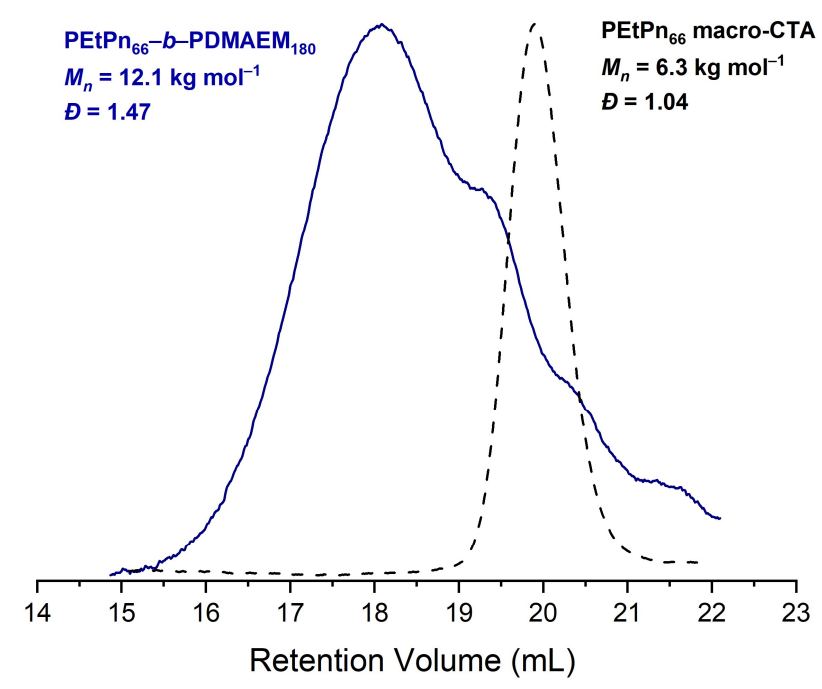

Figure S27. SEC elugrams $\left(2 \mathrm{mg} \mathrm{mL}^{-1}\right)$ (normalized RI) of isolated PEtPn $66-b-$ PDMAEMA $_{130}$ (blue, $D=$ 1.47) quenched after $24 \mathrm{~h}$ (ca. $90 \%$ conversion) and $\mathrm{PEtPn}_{66}$ macro-CTA (black, $D=1.04$ ) (measured in $\operatorname{DMF}(0.1 \mathrm{M} \mathrm{LiCl})$ at $\left.60^{\circ} \mathrm{C}\right)$.

\section{Synthesis of $\mathrm{PEtPn}_{66}-b-\mathrm{P} 2 \mathrm{VP} \mathrm{P}_{170}$}

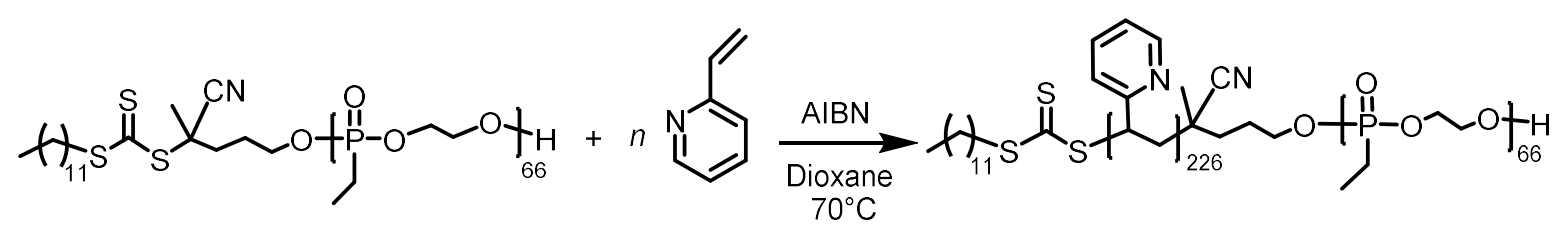

Scheme S9. Synthesis of $\mathrm{PEtPn}_{66}-b-\mathrm{P} 2 \mathrm{VP}_{170}$ by RAFT polymerization.

PEtPn $_{66}$ macro-CTA (89 mg, $0.01 \mathrm{mmol}, 1 \mathrm{eq}$ ) and 2-vinyl pyridine (2VP) (212 mg, $\left.2.01 \mathrm{mmol}, 200 \mathrm{eq}\right)$ were dissolved in dioxane $(0.6 \mathrm{~mL})$ in a Schlenk flask. A stock solution of AIBN $\left(10 \mathrm{mg} \mathrm{mL}^{-1}\right)$ was prepared and AIBN $(0.33 \mathrm{mg}, 0.002 \mathrm{mmol}, 0.2 \mathrm{eq})$ was added. The reaction mixture was stirred at room temperature followed by three freeze-pump-thaw cycles. The Schlenk flask was placed in a preheated oil bath at $70{ }^{\circ} \mathrm{C}$ for $16 \mathrm{~h}$. Finally, the flask was placed in liquid nitrogen until frozen and opened to air to terminate the polymerization. The crude product was purified by precipitation into hexanes three times, and drying in vacuo to yield $\mathrm{PEtPn}_{62}-b-\mathrm{P} 2 \mathrm{VP}_{170}$ as a light yellow solid (0.06 g, $\left.33 \%\right)$. 


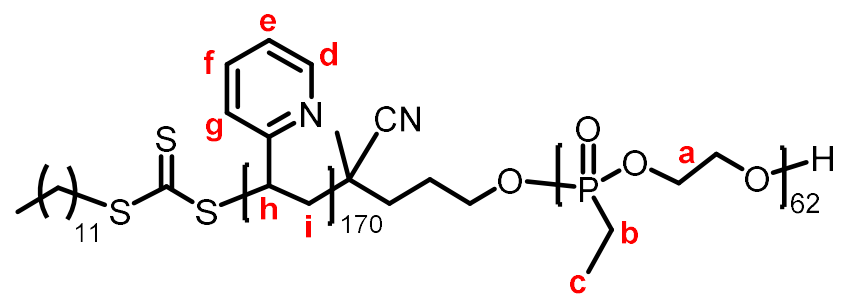

${ }^{1} \mathrm{H}$ NMR $\left(\mathrm{CDCl}_{3}\right): \delta$ (ppm) 8.48-8.02 (m, Hd, $\left.170 \mathrm{H}\right)$; 7.34-6.10 (m, He, Hf, Hg, $\left.524 \mathrm{H}\right)$; 4.32-4.15 (m, Hb, $264 \mathrm{H}), 2.66-2.18$ (s, Hh, $170 \mathrm{H}) ; 1.25-1.15$ (m, Hb, Hi, $597 \mathrm{H})$. End-group ${ }^{1} \mathrm{H}$ NMR spectroscopy analysis showed $D P_{n}=170$ for $2 \mathrm{VP}$ is based on 'a' (backbone $-\mathrm{CH}_{2}-\mathrm{CH}_{2}$ ) (Fig. S28).

${ }^{31} \mathrm{P}$ NMR ( $\left.\mathrm{CDCl}_{3}\right): \delta(\mathrm{ppm}) 35.2$ (Fig. S29).

SEC: $M_{\mathrm{n}}=16,200 \mathrm{~g} / \mathrm{mol} ; \varnothing=1.31$ (Fig. S31).

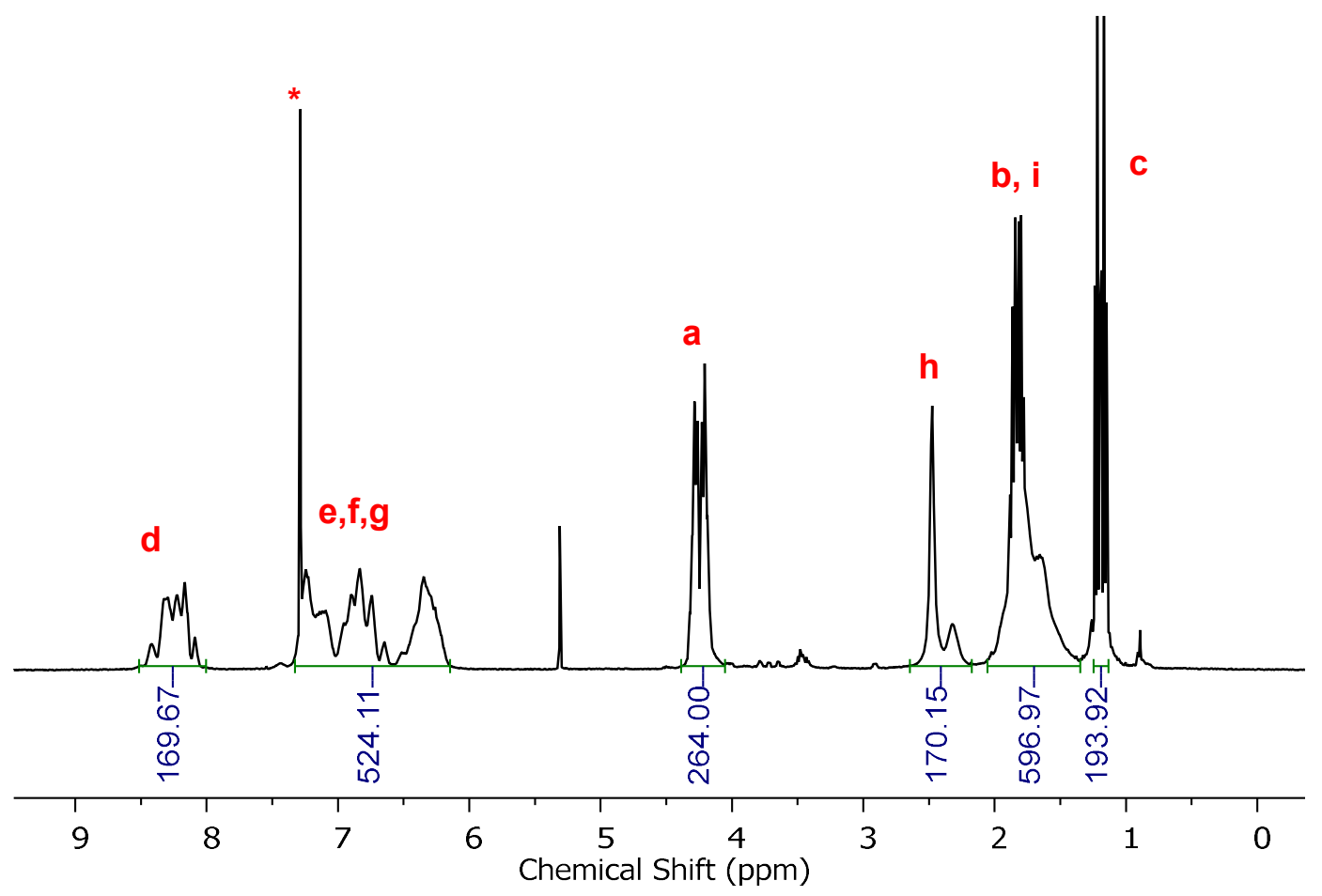

Figure S28. ${ }^{1} \mathrm{H}$ NMR $\left(400 \mathrm{MHz}, \mathrm{CDCl}_{3}\right)$ spectrum of $\mathrm{PEtPn}_{66}-b-\mathrm{P} 2 \mathrm{PV}_{170}$. Deuterated solvent residual signal denote by *. 


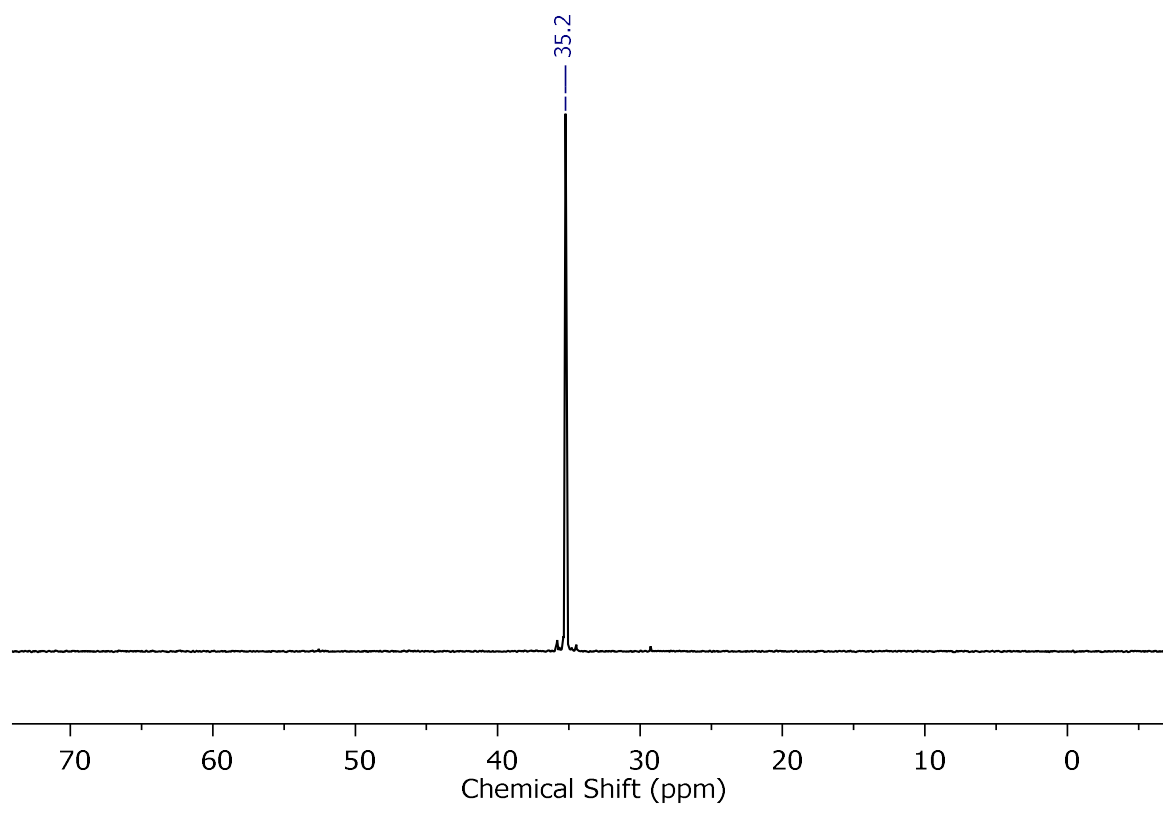

Figure S29. ${ }^{31} \mathrm{P}$ NMR $\left(162 \mathrm{MHz}, \mathrm{CDCl}_{3}\right)$ spectrum of $\mathrm{PEtPn}_{66}-b-\mathrm{P}_{2} \mathrm{PV}_{170}$.

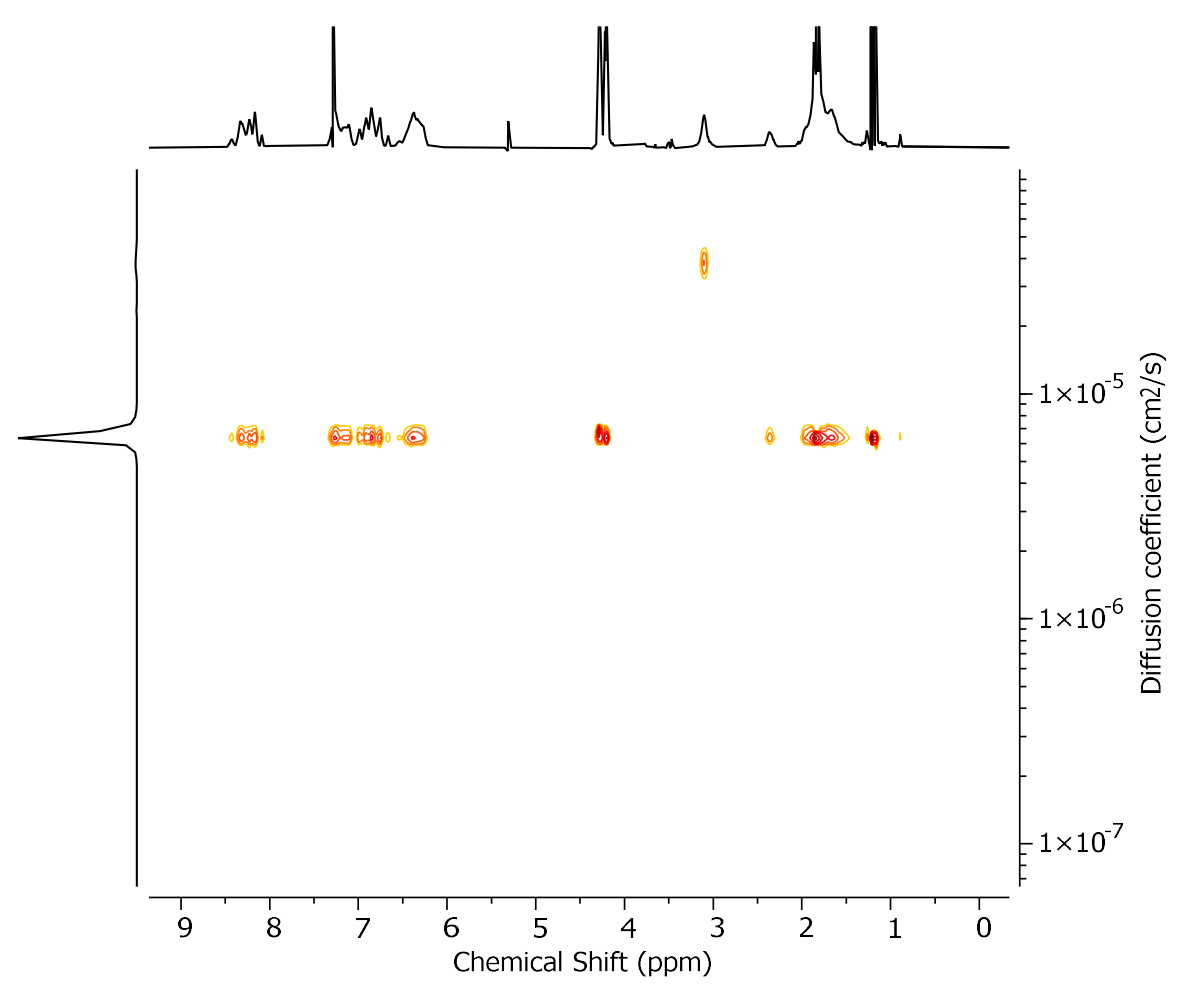

Figure S30. ${ }^{1} \mathrm{H}$ DOSY NMR (600 MHz, $\left.\mathrm{CDCl}_{3}\right)$ spectrum of $\mathrm{PEtPn}_{66}-b-\mathrm{P} 2 \mathrm{PV}_{170}$. 


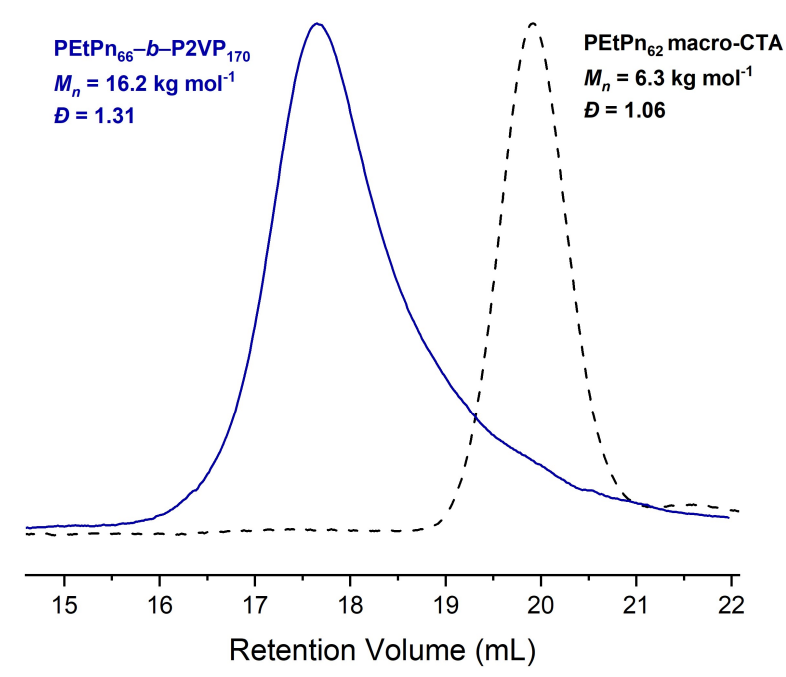

Figure S31. SEC elugrams $\left(2 \mathrm{mg} \mathrm{mL}^{-1}\right)$ (normalized RI) of isolated $\mathrm{PEtPn}_{66}-b-\mathrm{P} 2 \mathrm{PV}_{170}$ (blue, $D=1.31$ ) and PEtPn 6 macro-CTA (black, $\bigoplus_{\mathrm{m}}=1.06$ ) (measured in DMF $(0.1 \mathrm{M} \mathrm{LiCl})$ at $60{ }^{\circ} \mathrm{C}$ ).

\section{Synthesis of $\operatorname{PEtPn}_{62}-b-\mathbf{P S}_{345}$ by aqueous emulsion polymerization}

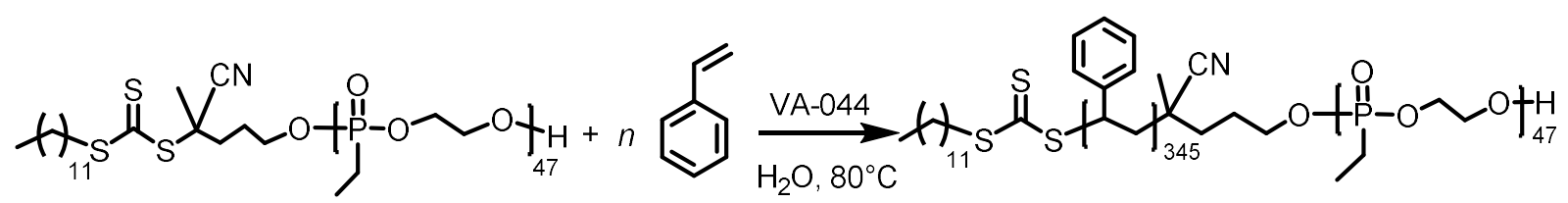

Scheme S10. Synthesis of $\mathrm{PEtPn}_{62}-b-\mathrm{PS}_{345}$ by aqueous RAFT polymerization.

$\operatorname{PEtPn}_{62}$-CTA macroinitiator (129 mg, $\left.0.01 \mathrm{mmol}, 1 \mathrm{eq}\right)$ and deionized water $(2.73 \mathrm{~g}, 20 \mathrm{w} / \mathrm{w} \%)$ were placed in a Schlenk flask and stirred until the macroinitiator was completely dissolved. A stock solution of VA-044 (10 $\left.\mathrm{mg} \mathrm{mL}^{-1}\right)$ was prepared and VA-044 $(1.57 \mathrm{mg}, 0.002 \mathrm{mmol}, 0.3 \mathrm{eq})$ was added to the reaction mixture. Styrene $(0.53 \mathrm{~g}, 5.11 \mathrm{mmol}, 350 \mathrm{eq})$ was weighed into a separate vial and added to the solution followed by stirring $(1500 \mathrm{rpm})$ for $30 \mathrm{~min}$. Then, the Schlenk flask was immersed in an ice bath and the solution was deoxygenized with nitrogen for $30 \mathrm{~min}$ and then immersed in an oil bath at $80^{\circ} \mathrm{C}$ for $23 \mathrm{~h}$. Finally, the flask was placed in an ice bath and opened to air to terminate the polymerization. 


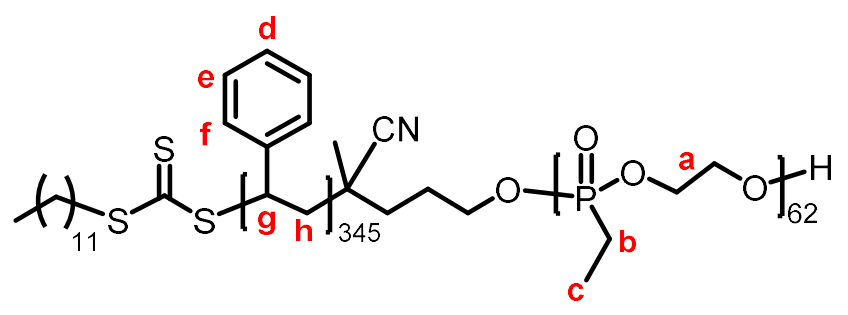

${ }^{1} \mathrm{H}$ NMR $\left(\mathrm{CDCl}_{3}\right): \delta(\mathrm{ppm})$ 7.24-6.24 (m, Hd, He, Hf, $\left.1730 \mathrm{H}\right)$; 4.35-4.15 (m, Ha, $\left.248 \mathrm{H}\right) ;$ 2.03-1.14 (m, $\mathrm{Hb}, \mathrm{Hc}, \mathrm{Hg}, \mathrm{Hh}, 1417 \mathrm{H}$ ). End-group ${ }^{1} \mathrm{H}$ NMR spectroscopy analysis showed $D P_{n}=345$ is based on 'a' (backbone $-\mathrm{CH}_{2}-\mathrm{CH}_{2}$ ) (Fig. S32).

${ }^{31} \mathrm{P} \mathrm{NMR}\left(\mathrm{CDCl}_{3}\right): \delta(\mathrm{ppm}) 35.2$ (Fig. S33).

SEC: $M_{\mathrm{n}}=35,500 \mathrm{~g} / \mathrm{mol} ; \varnothing=1.25$ (Fig. S35).

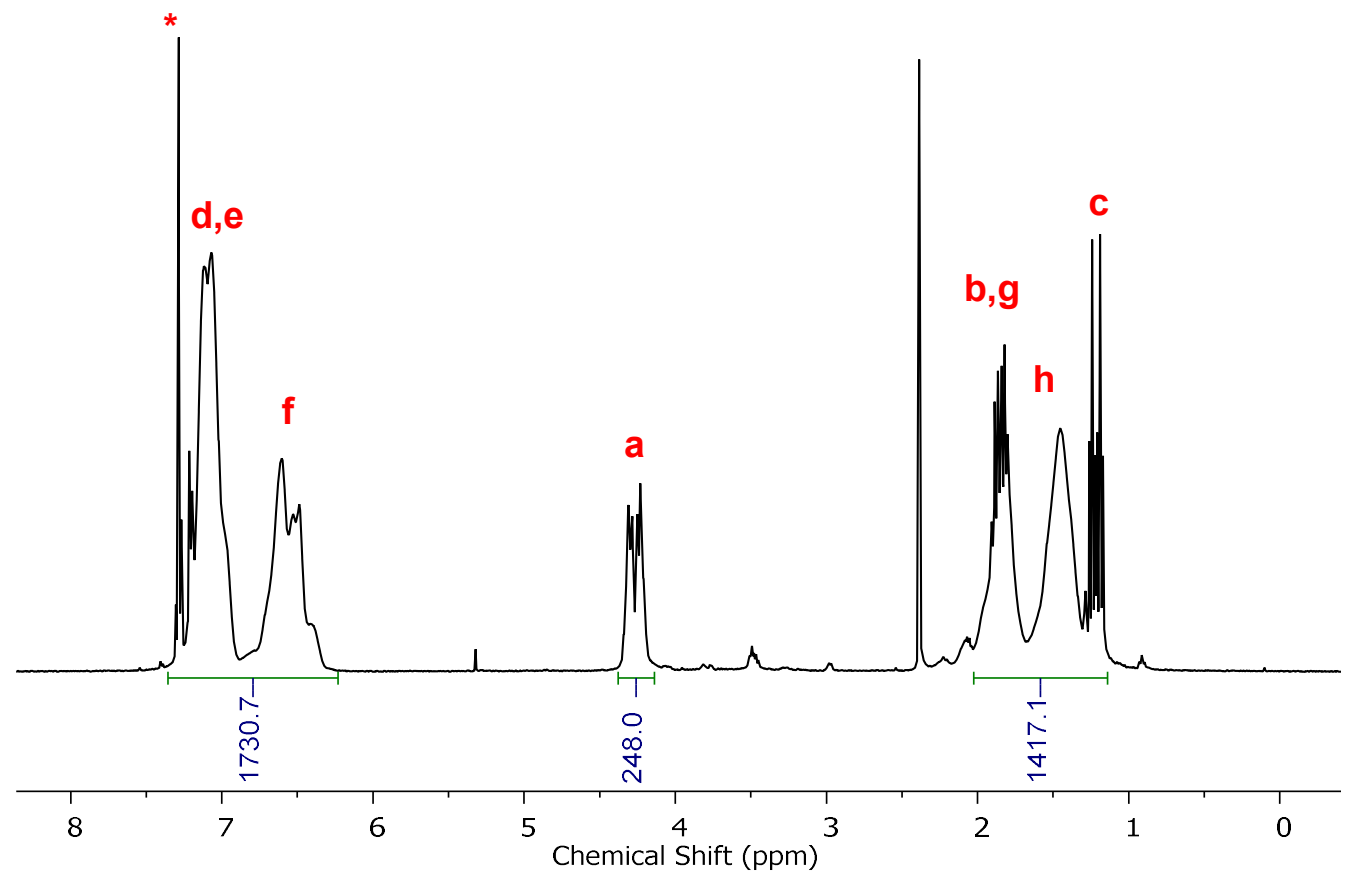

Figure S32. ${ }^{1} \mathrm{H}$ NMR $\left(400 \mathrm{MHz}, \mathrm{CDCl}_{3}\right)$ spectrum of $\mathrm{PEtPn}_{62}-b-\mathrm{PS}_{345}$. Deuterated solvent residual signal denote by *. 


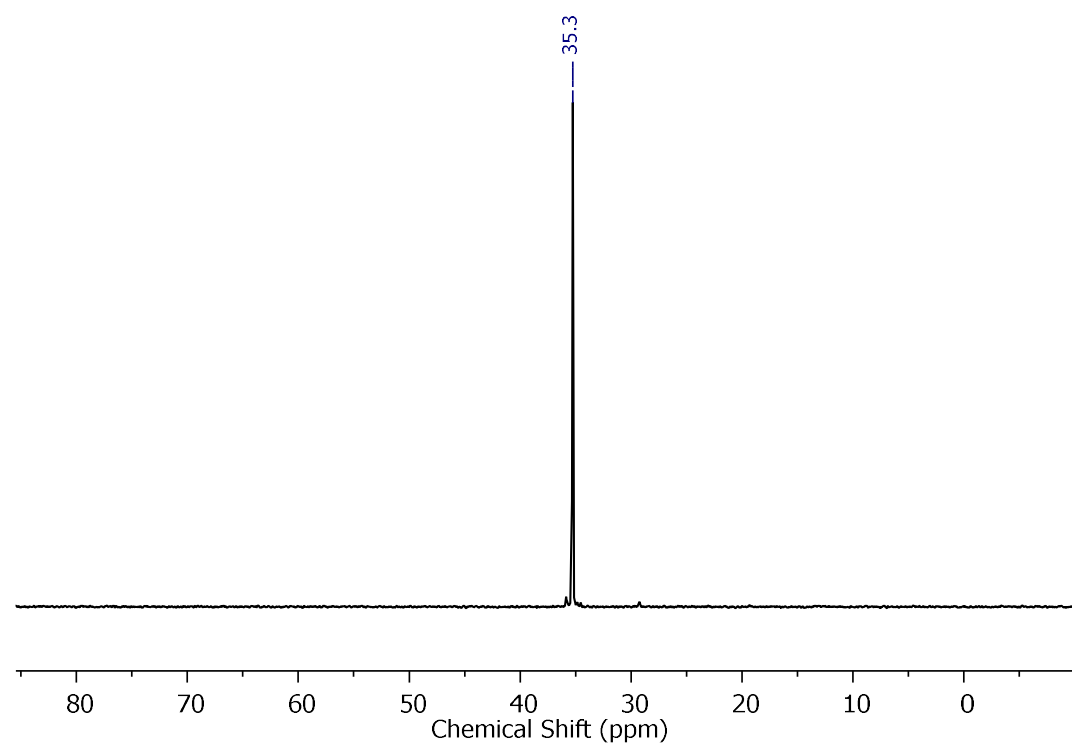

Figure S33. ${ }^{31} \mathrm{P}$ NMR $\left(162 \mathrm{MHz}, \mathrm{CDCl}_{3}\right)$ spectrum of $\mathrm{PEtPn}_{62}-b-\mathrm{PS}_{345}$.

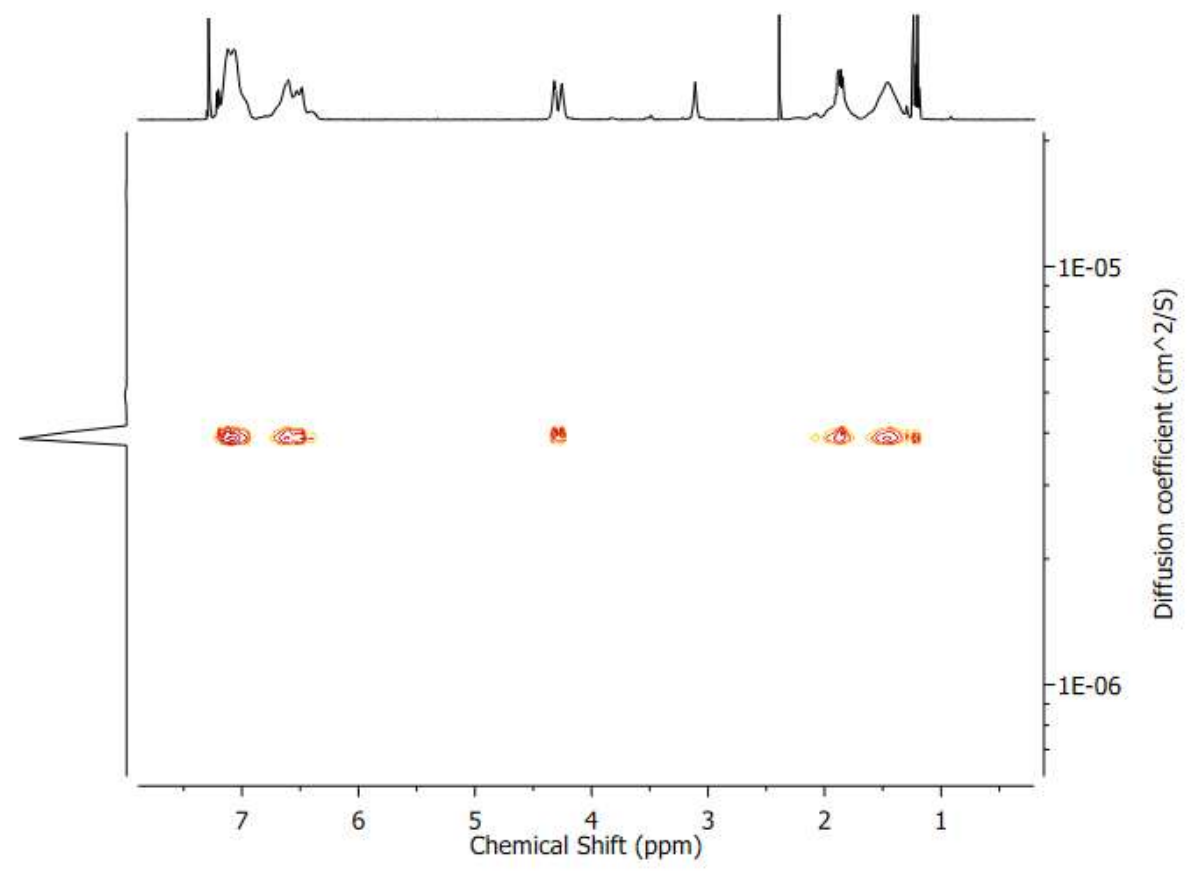

Figure S34. ${ }^{1} \mathrm{H}$ DOSY NMR (600 MHz, $\mathrm{CDCl}_{3}$ ) spectrum of $\mathrm{PEtPn}_{62}-b-\mathrm{PS}_{345}$. Deuterated solvent residual signal denote by * 


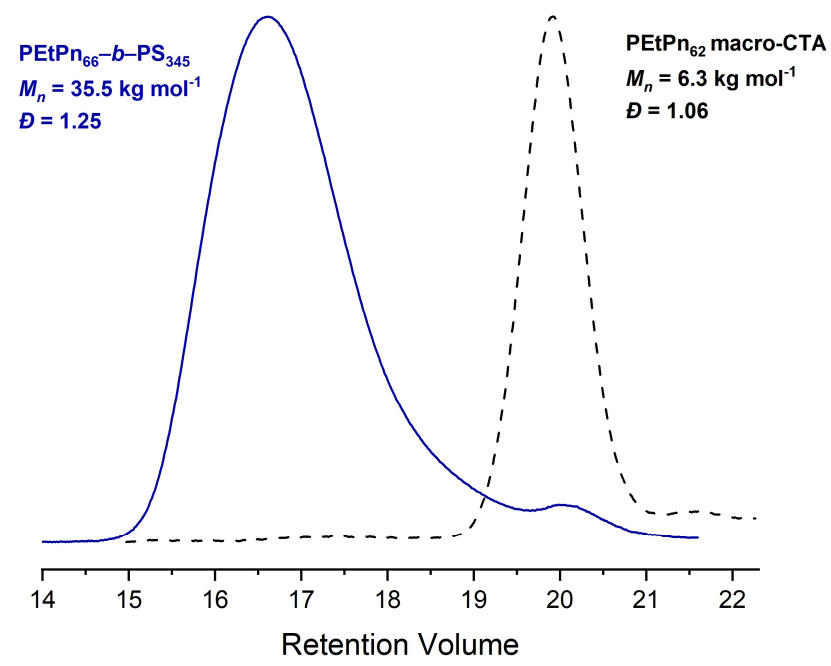

Figure S35. SEC elugrams $\left(2 \mathrm{mg} \mathrm{mL}^{-1}\right)$ (normalized RI) of isolated $\mathrm{PEtPn}_{65}-b-\mathrm{PS}_{206}$ (blue, $D=1.25$ ) and PEtPn $_{62}$ macro-CTA (black, $D=1.06$ ) (measured in DMF $(0.1 \mathrm{M} \mathrm{LiCl})$ at $60{ }^{\circ} \mathrm{C}$ ).

\section{References}

S1. Arno, M. C.; Inam, M.; Coe, Z.; Cambridge, G.; Macdougall, L. J.; Keogh, R.; Dove, A. P.; O'Reilly, R. K., Precision Epitaxy for Aqueous 1D and 2D Poly(E-caprolactone) Assemblies. J. Am. Chem. Soc. 2017, 139, 16980-16985.

S2. Wolf, T.; Steinbach, T.; Wurm, F. R., A Library of Well-Defined and Water-Soluble Poly(alkyl phosphonate)s with Adjustable Hydrolysis. Macromolecules 2015, 48, 3853-3863.

S3. Hampu, N.; Werber, J. R.; Hillmyer, M. A., Co-Casting Highly Selective Dual-Layer Membranes with Disordered Block Polymer Selective Layers. ACS Appl. Mater. Interfaces 2020, 12, 45351-45362.

S4. Griffin, W. C., Classification of surface-active agents by HLB. J. Soc. Cosmet. Chem. 1949, 1, 311 326.

S5. $\quad$ Bauer, K. N.; Simon, J.; Mailänder, V.; Landfester, K.; Wurm, F. R., Polyphosphoester surfactants as general stealth coatings for polymeric nanocarriers. Acta Biomater. 2020, 116, 318-328. 